\title{
ReVisión de la familia Polytrichaceae (Bryophyta) PARA Colombia
}

\author{
ANGÉLICA APONTE1*-R. y JAIME URIBE-M. ${ }^{1}$
}

\begin{abstract}
Summary: The taxonomic revision of the family Polytrichaceae for Colombia is presented. Seventeen species are recognized for the country. Steereobryon elamellosum is recorded for the first time for the country. The representation of species is modified in the cases of Atrichum, Polytrichum, Pogonatum, Polytrichadelphus and Steereobryon; the representation of Notoligotrichum and Oligotrichum is confirmed. Fifteen new synonyms are proposed. The review includes a general key for family, synonymy, descriptions, illustrations and distribution maps.
\end{abstract}

Key words: Acrocarpic mosses, Andean forest, paramo.

Resumen: Se presenta la revisión taxonómica de la familia Polytrichaceae para Colombia. Diez y siete especies son reconocidas para el país. Se registra a Steereobryon elamellosum por primera vez para el país; se modifica la representación de especies en los casos de Atrichum, Polytrichum, Pogonatum, Polytrichadelphus y Steereobryon; se confirma la representación de Notoligotrichum y Oligotrichum. Se proponen quince nuevos sinónimos. La revisión incluye una clave general para los géneros de la familia, sinonimia, descripciones, ilustraciones y mapas de distribución.

Palabras clave: Bosque andino, musgos acrocárpicos, páramo.

\section{INTRODUCCIÓN}

La familia Polytrichaceae está ampliamente distribuida en el planeta, las especies son un importante componente de comunidades vegetales pioneras (Churchill, 2009; Hyvönen, 2012). Schwägrichen (1830) describió a la familia Polytrichaceae mencionando la presencia de lamelas sobre las hojas, ramas reproductivas apicales, perigonios discoides, cápsulas anguladas, cilíndricas, semianguladas o teretes, caliptra pilosa o glabra, con una columnela membranácea y epifragma plano.

Hampe (1865), publicó el primer inventario sobre los musgos neotropicales, Mitten (1869) publicó uno de los tratamientos taxonómicos más importantes para el grupo y de alta relevancia para la región. Smith (1971) detalló las características morfológicas de la familia, los géneros existentes y sus variaciones a

\footnotetext{
${ }^{1}$ Instituto de Ciencias Naturales, Facultad de Ciencias, Universidad Nacional de Colombia, Sede Bogotá, Bogotá D.C., Colombia

*Autor para correspondencia: angeponte@gmail.com
}

nivel mundial, adicionalmente describió a Itatiella, Notoligotrichum, Polytrichastrum y Steereobryon.

Se considera que la mayor diversidad de Polytrichaceae se encuentra en el Sudeste de Asia y en Sudamérica (Goffinet et al., 2009; Hyvönen, 2012). Actualmente, está conformada por 23 géneros (Goffinet et al., 2009). Para América tropical, Gradstein et al. (2001) reportaron 10 géneros y 61 especies. En el caso de los Andes tropicales, Churchill et al. (2000, 2009) reconocieron 9-10 géneros y 23-45 especies, Polytrichadelphus, Pogonatum y Polytrichum han sido los géneros con mayor cantidad de especies. Los inventarios regionales, han demostrado que el norte de Sudamérica concentra una gran cantidad de especies (Steere, 1948; Pursell, 1973; Griffin III, 1975; Hermann, 1976; Churchill et al., 2000; Morales \& García, 2006; Churchill et al., 2009; O'Shea, 2010; Peralta \& Yano, 2010; Costa et al., 2011), recientemente, Churchill (2016) registró para Colombia 22 especies agrupadas en ocho géneros. En este trabajo se busca dilucidar la representación de la familia para Colombia y determinar si se trata de alta riqueza o variación morfológica. 


\section{Materiales y Métodos}

Se estudiaron las colecciones de Polytrichaceae, así como los especímenes tipo de las especies con presencia en Colombia y de distribución geográfica próxima depositados en los herbarios BM, CAUP, COAH, COL, CUVC, HUA, JE, NY, P y PSO.

Para el estudio de los ejemplares, se utilizó un estereomicroscopio Advanced Instrument y un microscopio de luz transmitida Olympus CH20. El análisis e identificación de las muestras se llevó a cabo mediante la realización de cortes a mano alzada. En el gametofito, se estudiaron el rizoma, el tallo, las hojas, los perigonios y periquecios. En el esporofito se observaron la seta, la cápsula, el exotecio, el peristoma, el opérculo y la caliptra. Se determinó como "plantas pequeñas" aquellas con tamaño del gametofito menor a $2 \mathrm{~cm}$, "plantas medianas" aquellas mayores de $2 \mathrm{~cm}$ hasta $7 \mathrm{~cm}$ y "plantas grandes" de más de $7 \mathrm{~cm}$.

\section{Resultados}

\section{Tratamiento taxonómico}

\section{Polytrichaceae}

Polytrichaceae Schwägr., Species Muscorum Frondosorum 1. En C.L. von Wildenow, Sp. Pl. 5(2):1. 1830.

Tipo: Polytrichum Hedw.

Plantas pequeñas (de $3 \mathrm{~mm}$ ) hasta muy grandes (más de $30 \mathrm{~cm}$ ). Tallos erectos; rígidos, simples o ramificados por innovaciones; con una banda central polytrichoide. Rizoides predominantemente abundantes. Hojas lanceoladas, liguladas o predominantemente deltoides, o diferenciadas en una vaina amplectante y un limbo estrecho a anchamente lanceolado; margen del limbo plano erecto o incurvado, entero hasta fuertemente serrado, dientes simples, unicelulares, multicelulares o dobles; costa simple percurrente a largo excurrente, robusta, generalmente con dientes sobre el dorso; limbo plano, ocasionalmente crispado, con células isodiamétricas de paredes engrosadas; vaina uniestratificada, con células rectangulares a lineales, de pared delgada, amarillas o anaranjadas; lamelas en la superficie adaxial de la hoja, sobre el nervio o cubriendo casi todo el limbo; dispuestas en filas continuas o discontinuas; de 1-8 células de alto; células apicales isomórficas o diferenciadas y con forma de U, piriformes, cuadradas o como silla de montar; simples o geminadas; ocasionalmente papilosas.

Generalmente Dioicas. Periquecio terminal; hojas periqueciales con vaina larga a casi acintada; paráfisis uniseriadas filiformes, escasas casi nulas a abundantes; Perigonio cupuliforme; ocasionalmente con innovaciones sucesivas; hojas perigoniales diferenciadas en varias series; limbo reducido gradualmente; vaina amplia; anteridios abundantes; con paráfisis filiformes o clavadas, generalmente numerosas. Esporofitos solitarios o 1-2 por periquecio. Seta terminal o pseudolateral por innovaciones periqueciales, generalmente recta; lisa; anaranjada, rojiza o pardo oscura. Cápsula erecta a levemente inclinada u horizontal; terete, cilíndrica o angulada, de 2-4 aristas; cuello diferenciado en una apófisis o indiferenciado; estomas presentes en la base de la cápsula o hasta $1 / 4$ de la superficie de la misma o ausentes. Peristoma simple; dientes del peristoma unidos al epifragma (ápice de la columela expandido), 32 o 64; ápice agudo u obtuso; en ocasiones curvados hacia adentro; hialinos o pigmentados de rojo o anaranjado. Opérculo rostrado o largo rostrado, amarillo, rojizo o pardo. Caliptra mitrada o cuculada; pilosa o glabra; pardo oscuro, anaranjada o amarillo dorada.

\section{Clave para los géneros de la familia Polytrichaceae en Colombia}

1. Hojas deltoides, diferenciadas en vaina y limbo..2

1'. Hojas liguladas, ovadas o triangulares, poco o nada diferenciadas en vaina y limbo. ................ 6

2. Hombros diferenciados. ..................................... 3

2'. Hombros indiferenciados. ....... Pogonatum (p.p)

3. Vaina con una porción o toda la superficie de color anaranjado. Polytrichadelphus

3'. Vaina de color amarillo. 4

4. Células apicales de las lamelas papilosas. Polytrichastrum

$4^{\prime}$. Células apicales de las lamelas lisas. 5

5. Limbo linear o triangular. Polytrichum

5'. Limbo oblongo. Pogonatum (p.p) 
6. Margen diferenciado. 7

$6{ }^{\prime}$. Margen no diferenciado. ... 8

7. Margen con dientes dobles, células lisas.

Atrichum

7'. Margen con dientes simples, células papilosas. .. Steereobryon

8. Margen serrado. Pogonatum (p.p)

$8^{\prime}$. Margen entero o con pequeños dientes ocasionales. .. 9

9. Lamelas sobre la costa. Dientes en el margen, escasos conformados por una sola célula más grande que las circundantes. Hojas delicadas y quebradizas.

Oligotrichum

9'. Lamelas sobre la costa y parte de la lámina. Margen del limbo entero. Hojas fuertes y resistentes. Notoligotrichum

Atrichum P. Beauv.

Atrichum P. Beauv., Mag. Encycl. 5:329.1804. nom. cons.

Catharinea Ehrh. ex F.Weber \& D. Mohr, Obs. Bot. 31, 1803; nom. rejic.

Tipo: Catharinea undulata (Hedw.) F. Weber \& D. Mohr [= Atrichum undulatum (Hedw.) P. Beauv]

\section{Atrichum androgynum (Müll.Hal.) A. Jaeger}

Atrichum androgynum (Müll. Hal.) A. Jaeger. Ber. Thätigk. St. Gallischen. Naturwiss. Ges.: 241. 1875. Catharinea androgyna Müll. Hal., Syn. Musc. Frond.1: 193. 1848., Tipo: Sudáfrica. Ecklon (Hb. Kunz.). Fig.1

Catharinea polycarpa Müll. Hal., Syn. Musc. Frond.2: 558.1851; Atrichum polycarpum (Müll. Hal.) Mitt., J. Linn. Soc., Bot. 12: 604. 1869. Tipo: México, Liebmann 42 (BM 960452!, NY 596454!).

Catharinea oerstediana Müll. Hal., Syn. Musc. Frond.2: 558.1851; Atrichum oerstedianum (Müll. Hal.) Mitt., J. Linn. Soc., Bot. 12: 605. 1869. Atrichum undulatum var. oerstedianum (Müll.Hal.) H.A. Crum, Bryologist 74: 166. 1971; Syn. Nov., Atrichum androgynum var. oerstedianum (Müll. Hal.) Nyholm, Lindbergia 1: 26. 1971. Tipo: Costa Rica, Oersted s.n (JE4004416!). Syn. Nov.
Catharinea synoica Müll. Hal., Bull. Herb. Boissier 5: 549. 1897. Atrichum synoicum (Müll. Hal.) Paris, Index Bryol. Suppl. 17. 1900. Tipo: Jamaica, Harris 10071 (BM 960455!)

Catharinea nigricans Müll. Hal.ex Herzog, Biblioth. Bot 87: 102. 1916. Atrichum nigricans (Müll. Hal. ex Herzog) F.J. Herm. Bryologist 79: 160. 1976. Tipo: Bolivia, Herzog 5136 (JE 4004416!).

Plantas medianas de hasta $6 \mathrm{~cm}$ de longitud; verde amarillentas a pardo verdosas. Tallo simple o ramificado. Hojas de 5-8 x 1-1,5 mm; lineares, oblongo lanceoladas a liguladas; fuertemente onduladas, con espinas dorsales; margen plano, diferenciado (limbado), dentado hacia el ápice, dientes dobles; ápice agudo o corto acuminado a triangular; base de la hoja levemente amplectante; nervio subpercurrente a percurrente, espinoso en el envés del 1/4 apical; lamelas sobre el nervio; en sección transversal, 4-6 filas de lamelas de 2-4 células de alto, célula lamelar apical indiferenciada, de pared delgada, lisa, de 10-20 $\mu \mathrm{m}$ de ancho. Células de la epidermis ventral de 5-20 x 10-15 $\mu \mathrm{m}$; células de la epidermis dorsal de 3-10 x 5-15 $\mu \mathrm{m}$; células del limbo de 10-25 x 10$25 \mu \mathrm{m}$, hacia la base de $20-30 \times 5-20 \mu \mathrm{m}$.

Monoicas o Dioicas. Esporofito 1-3(-4), en el mismo gametoceo. Seta rojiza o parda, de $2-4 \mathrm{~cm}$ de largo, recta. Cápsula erecta, terete, de 4-7,5 mm de largo; células del exotecio de 70-110 x 15$30 \mu \mathrm{m}$. Peristoma de 32 dientes, de 100-150 x 10$15 \mu \mathrm{m}$. Caliptra cuculada, de hasta $7 \mathrm{~mm}$, parda o pardo amarillenta, glabra con espinas en el ápice.

Material estudiado. COLOMBIA. Dpto. Antioquia, Sonsón. 2660 m, 22-VI-85, Churchill 12935 (COL, HUA, NY); Dpto. Boyacá, Arcabuco.2550-2600 m, 11-V-96, Aguirre 11528 (COL); Dpto. Caldas, Pácora. 1840 m, 23-XII-85, Pérez 642 (HUA); Dpto. Cauca, Popayán, 2²6’N 76³1'W, 2000 m, 12-I-91, Churchill 17344 (COL-HUA-NY); Dpto. Cundinamarca, Pacho, 2470 m, 25-VIII-92, Linares 3657 (COLHUA-NY); Dpto. Huila, San Agustín, 1730 m, 30III-72, Cleef 2621 (COL); Dpto. Magdalena, Santa Marta, 2100 m, 14-I-67, Mägdefrau 1086 (COL); Dpto. Nariño, Chachagüí, $1^{\circ} 23^{\prime} \mathrm{N} 77^{\circ} 16^{\prime} \mathrm{W}, 2450 \mathrm{~m}$, 21-IV-90, Ramírez 2392 (COL-NY); Dpto. Quindio, Salento, 2920-3240 m, 07-XI-91, Uribe 2281 (COL); 
Bol. Soc. Argent. Bot. 52 (2) 2017

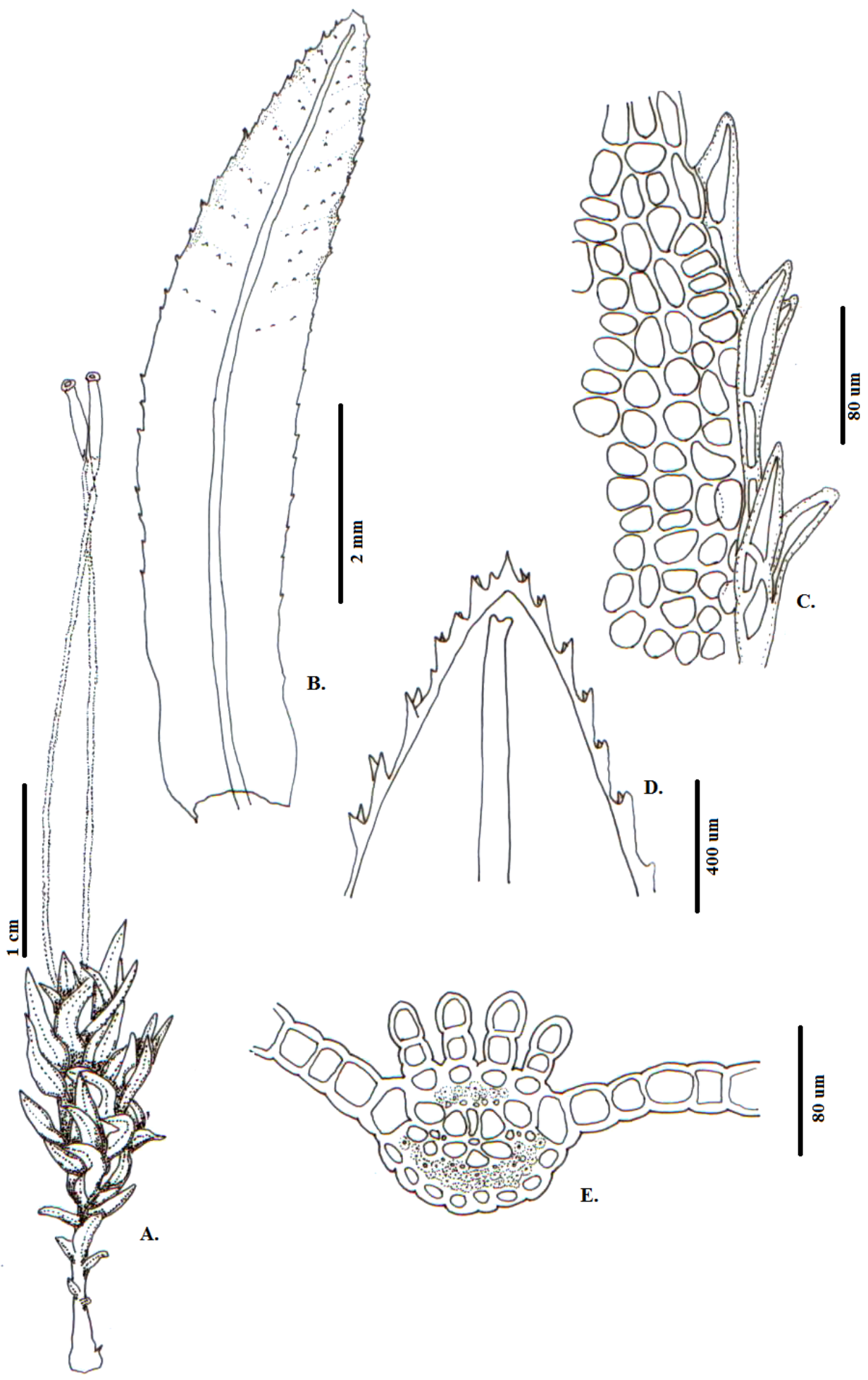

Fig. 1. Atrichum androgynum (Müll.Hal.) Jaeger: A. Hábito, B-E. Hoja, B. Vista ventral, C. Detalle del margen, D. Detalle del ápice, E. Corte transversal. [Todas de Churchill 12858] 
Dpto. Risaralda, Mistrató, 1915 m, 27-IV-92, Uribe 2506 (COL); Dpto. Santander, Suratá, 2900 m, 24VII-85, Escobar 223 (HUA); Dpto. Tolima, Santa Isabel. 2700 m, 31-VII-80, Van Reenen 1977 (COL); Dpto. Valle del Cauca, Cali, 3³0’N 76³5'W, 19802000 m, 22-VI-87, Churchill 15129 (COL-HUANY). BOLIVIA: Dpto. Santa Cruz, Vallegrande, 18³8'S 6402'W, $2450 \mathrm{~m}, 27-\mathrm{II}-02$, Churchill 21177 (COL). JAMAICA: Prov. Cinchona. XII 1896, Harris 11027 (BM); MÉXICO: Est. Veracruz, Huatusco, Liebmann 96 (BM); SUDÁFRICA: Prov. Cabo, $32^{\circ} 27^{\circ} \mathrm{S} 26^{\circ} 32^{\prime} \mathrm{E}, 1250 \mathrm{~m}, 21-\mathrm{I}-73$, Marshall 9232 (COL).

Distribución geográfica. En Colombia se encuentra en los departamentos de Antioquia, Boyacá, Caldas, Cauca, Cundinamarca, Huila, Magdalena, Nariño, Quindío, Risaralda, Santander, Tolima y el Valle del Cauca entre 1200-3200 m de altitud (Fig. 4). También ha sido reportada de México, Jamaica, Costa Rica, Venezuela, Ecuador, Bolivia, Brasil, Argentina, Chile, Sudáfrica, Este de Australia, Tasmania y Nueva Zelanda (Dixon, 1926; Nyholm, 1971; Schiavone, 1978; Churchill et al., 2000; Peralta \& Yano, 2010).

Hábitat. Común en bosque andino, frecuente en barrancos, bosques perturbados y bordes de quebradas, creciendo sobre suelo, arenisca, roca o troncos en descomposición. En sitios sombreados y húmedos.

Observación. Se distingue fácilmente por sus hojas crispadas cuando secas, el margen con dientes dobles, el limbo ondulado y con filas de espinas en la superficie abaxial. Para Colombia se habían registrado Atrichum oerstedianum y A. polycarpum (Churchill \& Linares, 1995; Churchill, 2016), luego de observar los ejemplares Tipo, en contraste con la propuesta de Nyholm (1971), se evidenció que la variación de los caracteres que comúnmente se utilizaron para separar estas especies, no ofrece el soporte necesario para considerar que sean entidades diferentes.

\section{Notoligotrichum G.L. Sm.}

Notoligotrichum G.L. Sm., Mem. New York Bot. Gard. 21(3): 50. 1971.

Tipo: Polytrichum australe Hook. f. \& Wilson [=Notoligotrichum australe (Hook. f. \& Wilson) G.L. Sm.]
Notoligotrichum trichodon (Hook. f. \& Wilson) G.L. Sm.

Notoligotrichum trichodon (Hook. f. \& Wilson) G.L. Sm., Mem. New York Bot. Gard. 21(3): 51. 1971. Polytrichum trichodon Hook. f. \& Wilson, London J. Bot. 6: 289. pl. 10. 1847. Tipo: Colombia, Purdie s.n. (BM960593!, 960591!, 960592! y 1099230!). Fig. 2

Psilopilum antarcticum var. densifolium Cardot \& Broth., Kongl. Svenska Vetensk. Acad. Handl., n.s. 63(10): 71. 1923. Tipo: Islas Maldivas, Halle 713 (P 131994!).

Plantas pequeñas de hasta $2 \mathrm{~cm}$ de longitud; pardo a pardo rojizas. Tallo simple. Hojas de 3-6 x 1-2 mm; lanceoladas a oblongo lanceoladas; margen plano, levemente inflexo hacia el ápice, entero; ápice agudo, apiculado o cuspidado; base de la hoja levemente amplectante; nervio, excurrente, con algunos dientes pequeños en el envés del $1 / 4$ apical; lamelas sobre el nervio y parte de la lámina; en sección transversal, 20-50 filas de lamelas discontinuas de 5-10 células de alto, célula lamelar apical diferenciada, de varias formas en un mismo corte, desde piriforme hasta redondeadas, de pared delgada, lisa, de 5-15 $\mu \mathrm{m}$ de ancho. Células de la epidermis ventral de 5-10 x 10-20 $\mu \mathrm{m}$; células de la epidermis dorsal de 2-10 x 5-15 $\mu \mathrm{m}$; células de la lámina de 5-15 x 5-20 $\mu \mathrm{m}$; células de la base de $15-50 \times 5-20 \mu \mathrm{m}$.

Dioicas. Periquecio terminal; arquegonios abundantes; hojas periqueciales poco diferenciadas, de 6-7 x 1-2 mm, margen entero, ápice agudo a aristado; paráfisis filiformes, escasas. Perigonio terminal; anteridios abundantes, cilíndricos, de 1,5$2 \mathrm{~mm}$ de largo; hojas perigoniales diferenciadas, lanceoladas a orbiculares, de 2,5-3,5 x 1,5-2,5 mm, margen entero, ápice agudo; paráfisis clavadas, abundantes. Esporofito 1-2, en el mismo gametoceo. Seta lisa, roja o parda, de 1,5-4 cm de largo, recta. Cápsula erecta, asimétrica, subglobosa, levemente comprimida, de 2-6 mm de largo; células del exotecio de 25-100 x 15-30 $\mu \mathrm{m}$. Peristoma de 16 dientes. Caliptra cuculada, de hasta $5 \mathrm{~mm}$, parda, glabra en la base con espinas en el ápice.

Material estudiado. COLOMBIA. Dpto. Caldas, Nevado del Ruiz, 4300 m, 14-X-72, Florschütz. 4247 (COL); Dpto. Cauca, Puracé, 4000 m, 05- 
Bol. Soc. Argent. Bot. 52 (2) 2017

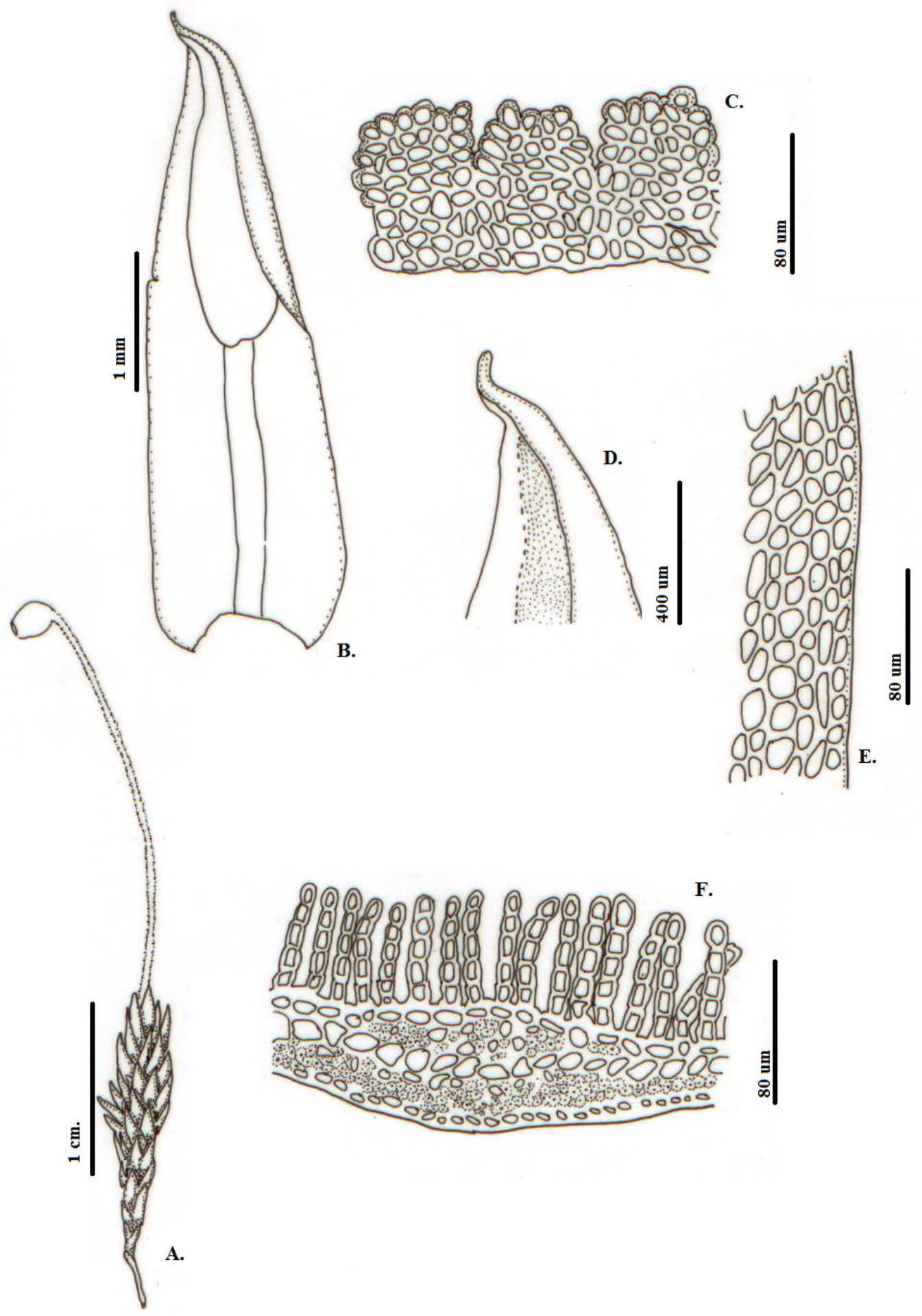

Fig. 2. Notoligotrichum trichodon (Hook.f. \& Wilson)G.L.Sm.: A. Hábito, B-F. Hoja, B. Vista general, C.Vista longitudinal de las lamelas, D. Detalle del ápice, E. Detalle del margen, F. Corte transversal. [A, B, C y D, de Lozano 4624; E y F, de Benavides 5269]. 
X-84, Lozano 4624 (COL-NY); Dpto. Nariño: Tuquerres, $1^{\circ} 04>\mathrm{N} 77^{\circ} 41>\mathrm{W}, 3600-3860 \mathrm{~m}, 25-\mathrm{II}-$ 95, Ramírez 6881 (COL).

Distribución geográfica. En Colombia se encuentra en los departamentos de Caldas, Cauca y Nariño entre 3600-4450 m de altitud (Fig. 4). También ha sido reportada de Ecuador, Bolivia (Churchill et al., 2000) y Argentina (Schiavone, 1993; Matteri \& Schiavone, 2002).

Hábitat: Se encuentra en las zonas altas de los páramos, en barrancos y sobre el suelo.

Observación. Se distingue fácilmente por las hojas triangulares, cóncavas, el margen entero y el ápice aristado. Notoligotrichum, fue propuesto por Smith (1971) para agrupar algunas especies robustas de Psilopilum; se reconoce porque sus hojas carecen de diferenciación en vaina y limbo, las lamelas se distribuyen en la costa y parte de la lámina, tiene cápsula globosa asimétrica y peristoma estrecho, compuesto por 16 dientes.

\section{Oligotrichum DC}

Oligotrichum DC. Fl. Franç. (ed. 3) 2: 491.1805. nom. cons.

Tipo: Polytrichum hercynicum Hedw. [=Oligotrichum hercynicum (Hedw.) Lam. \& DC.]

\section{Oligotrichum erosum (Hampe) Lindb.}

Oligotrichum erosum (Hampe) Lindb. Not. Sällsk.Fauna Fl. Fenn. Förh. 9: 103.1867. Catharinea erosa Hampe, Linnaea 32: 146. 1863. Tipo: Colombia, Lindig 2113 (BM 960444!, BM 960441 !, 960443 ! y 960445 !). Fig. 3

Plantas pequeñas de $1 \mathrm{~cm}$ de longitud; verde amarillentas a pardo verdosas. Tallo simple. Hojas de 4-5 x 1,5-2 mm en la zona media y de 1-1,5 mm ancho en la base; oblongo lanceoladas; margen plano, dentado hacia el ápice, dientes a partir de una célula diferenciada, pequeños; ápice agudo a obtuso; base de la hoja levemente amplectante; nervio percurrente, escabroso en el envés del $1 / 4$ apical; lamelas sobre el nervio; en sección transversal, 6-11 filas de lamelas, hasta 6-7 células de alto, célula lamelar apical poco diferenciada, a veces inflada, de pared delgada, lisa, de 12-15 $\mu \mathrm{m}$ de ancho. Células de la epidermis ventral, 5-15 x
5-20 $\mu \mathrm{m}$; células de la epidermis dorsal de 5-15 x 10-15 $\mu \mathrm{m}$; células de la lámina de 10-20 x 15-20 $\mu \mathrm{m}$; células de la base de 25-35 x 10-20 $\mu \mathrm{m}$.

Dioicas. Periquecio terminal; arquegonios escasos; hojas periqueciales poco diferenciadas, margen dentado en el tercio apical, ápice agudo; paráfisis no vistas. Perigonio no visto. Esporofito solitario. Seta lisa, roja o parda, de $2,5-5 \mathrm{~cm}$ de largo, recta. Cápsula erecta, ovoide, de 3,5-4 $\mathrm{mm}$ de largo; estomas en la base de la cápsula. Peristoma de 32 dientes. Caliptra cuculada, de hasta $5 \mathrm{~mm}$, parda, glabra en la base con espinas en el ápice.

Material estudiado. NUEVA GRANADA (Colombia, Cundinamarca). Manzanos ad Barrancos, 2600 m, Lindig 2113 (BM).

Distribución geográfica. En Colombia se conoce solo por el ejemplar tipo a $2600 \mathrm{~m}$ de altitud (Fig. 4). También se reporta para Costa Rica, Jamaica (Mullen \& Frey, 1947), Ecuador, Perú y Bolivia (Churchill et al., 2000).

Hábitat. Posiblemente se encuentre en los límites del bosque alto andino y páramo, sobre el suelo.

Observación. Se caracteriza por la hoja sin diferenciación en vaina y limbo, por la ausencia de margen diferenciado, por los dientes delicados, unicelulares en el tercio apical del margen de la hoja y por las lamelas ubicadas solamente sobre la costa. Sobre Oligotrichum erosum en Colombia, solo se cuenta con la información del ejemplar tipo: "Nova Granata, in. Silv. Manzanos ad Barrancos", por lo que se hizo necesario consultar sobre la región a la que correspondería. Para esto, se recurrió a la búsqueda en la Universidad de Harvard (Index of Botanical Specimens, 2015), en ello se encontró información de otros ejemplares colectados por Lindig, alrededor de 1860 y con números de colección cercanos, a partir de lo cual se puede determinar que el ejemplar fue colectado en Cundinamarca, Colombia, probablemente en el Páramo de Choachí, cerca a Bogotá

\section{Pogonatum P. Beauv.}

Pogonatum P. Beauv. Mag. Encycl. 5: 329. 1804.

Tipo: Polytrichum aloides Hedw. [= Pogonatum aloides (Hedw.) P. Beauv] 
Bol. Soc. Argent. Bot. 52 (2) 2017

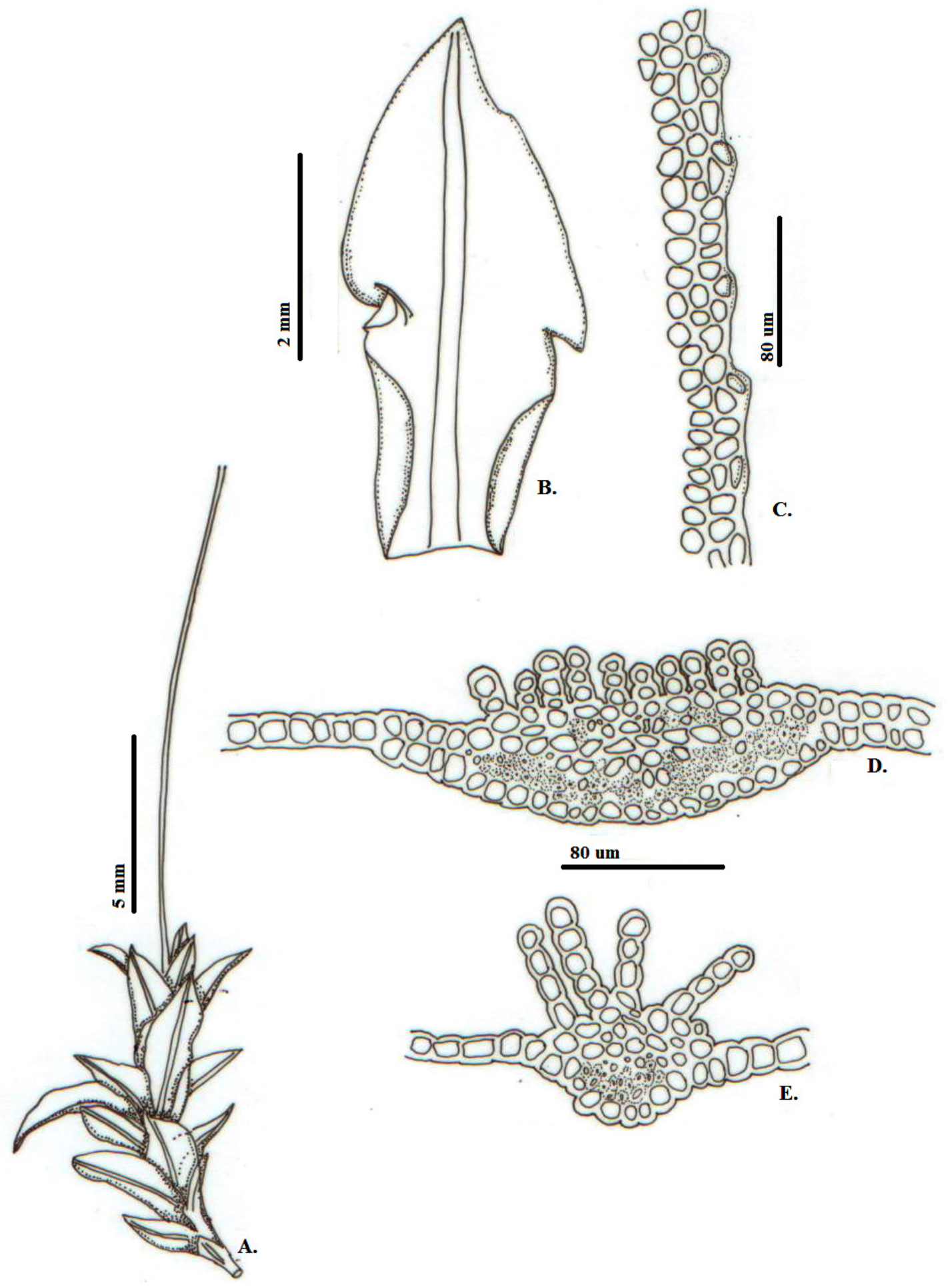

Fig. 3. Oligotrichum erosum (Hampe) Lindb., A.Hábito, B-E. Hoja, B. Vista general, C. Detalle del margen, D. Corte transversal en la zona media del limbo, E. Corte transversal cerca del ápice. [Todas de Lindig 2113, ejemplar Tipo, BM]. 
A. Aponte-R. y J. Uribe-M. - Revisión de la familia Polytrichaceae para Colombia

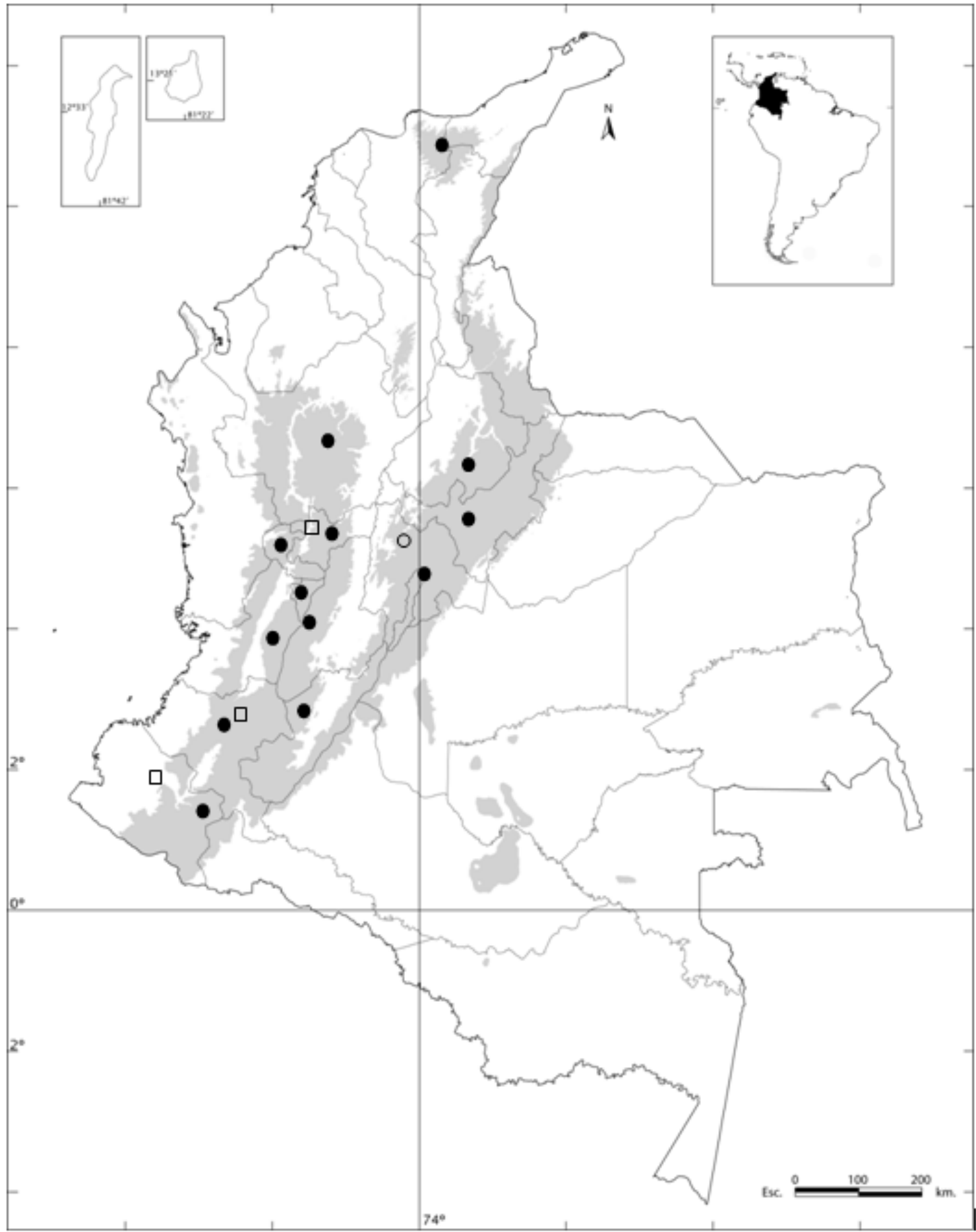

Fig. 4. Distribución geográfica departamental de Atrichum androgynum $(\bullet)$, Notoligotrichum trichodon ( $\square)$ y Oligotrichum erosum (o) en Colombia. 
Las principales características de las especies de Pogonatum se presentan en la Tabla 1.

\section{Clave para las especies colombianas de Pogonatum}

1. Células apicales de las lamelas geminadas. P. campylocarpum

$1^{\prime}$. Células apicales de las lamelas simples. .. 2

2. Células apicales de las lamelas cuadradas. P. perichaetiale subsp. oligodus

$2^{\prime}$. Células apicales de las lamelas redondeadas. ... 3

3. Lamelas sobre la costa. P. pensilvanicum

3'. Lamelas sobre la costa y parte de la lámina. .... 4

4. Margen fuertemente serrado, lamelas de 1 célula de alto. P. semipellucidum

$4{ }^{\prime}$. Margen irregular o levemente serrado, lamelas de 3 a 4 células de alto. P. tortile

\section{Pogonatum campylocarpum (Müll.Hal.)Mitt.}

Pogonatum campylocarpum (Müll.Hal.) Mitt. J. Linn. Soc., Bot. 12: 618. 1869. Polytrichum campylocarpum Müll. Hal. Syn. Musc. Frond. 1: 209. 1848. Tipo: Venezuela, Funck et Schlim 379 (Lectotipo designado por Menzel, 1985. BM!). Fig. 5

Polytrichum varians Hampe, Ann. Sci. Nat. Bot. sér. 5(4): 350. 1865; Pogonatum varians (Hampe) Mitt., J. Linn. Soc., Bot. 12: 616. 1869. Tipo: Colombia, Lindig s.n. (P 131714!).

Pogonatum arcuatum Mitt., J. Linn. Soc., Bot. 12: 617. 1869. Tipo: Colombia, Weir 207 (NY 1407856!, NY 1407857!).
Polytrichum neglectum Hampe, Bot. Zeit. 27: 867.1869. Pogonatum neglectum (Hampe) Jaeger, Ber. S. Gall. Naturw. Ges. 1873-74: 265. 1875. Tipo: Colombia, Lindig s.n. (BM 960501!, 960502!, 960503!, 960504! y 960505!).

Plantas pequeñas a grandes de hasta $7 \mathrm{~cm}$ de longitud; verde amarillento o pardo rojizo oscuro. Tallo simple o ramificado. Hojas de 1,5-9 x 0,5$2 \mathrm{~mm}$; deltoides; diferenciadas en vaina y limbo; limbo plano, de 1-7 $\mathrm{mm}$ de largo; margen involuto o erecto, leve a fuertemente serrado; ápice agudo o acuminado; vaina amplectante, ancha, amarilla o verde; nervio robusto, percurrente, espinoso en el envés; lamelas sobre el nervio y gran parte de la hoja; en sección transversal, 25-75 filas de lamelas de 2-7 células de alto, célula lamelar apical diferenciada, piriforme, geminada, de pared delgada, lisa, de 5-20 $\mu \mathrm{m}$ de ancho. Células de la epidermis ventral de 5-20 × 5-25 $\mu \mathrm{m}$; células de la epidermis dorsal de 2,5-10 x 5-20 $\mu$ m; células del limbo de 5-25 x 5-25 $\mu$ m; células de la vaina de 2090 x 5-20 $\mu \mathrm{m}$; células de la unión entre la vaina y el limbo de 2,5-20 x 7,5-20 $\mu \mathrm{m}$.

Dioicas. Periquecio terminal; arquegonios escasos; hojas periqueciales diferenciadas de 4-6 x 1-2 mm, margen serrado, ápice agudo; paráfisis filiformes, escasas. Perigonio terminal; anteridios abundantes, cilíndricos, de 0,5-2mm de largo; hojas perigoniales diferenciadas, lanceoladas a orbiculares, de 2,5-5 x 0,5-2 mm, margen y envés fuertemente serrados, ápice agudo, paráfisis filiformes, hialinas abundantes. Esporofito solitario. Seta lisa, roja, de 0,5-3 cm de largo, recta. Cápsula erecta, cilíndrica, de 2-3,5 mm de largo, ocasionalmente con costillas; células del exotecio

Tabla 1. Comparación entre algunas caracteristicas de las especies de Pogonatum presentes en Colombia.

\begin{tabular}{|lcccc|}
\hline \multicolumn{1}{|c}{ Especies } & $\begin{array}{c}\text { Células apicales } \\
\text { de las lamelas }\end{array}$ & $\begin{array}{c}\text { Forma de las células } \\
\text { apicales de las lamelas }\end{array}$ & $\begin{array}{c}\text { Forma de las hojas } \\
\text { del gametofito }\end{array}$ & $\begin{array}{c}\text { Altitud } \\
\text { P. campylocarpum }\end{array}$ \\
$\begin{array}{l}\text { Dobles } \\
\text { P. pensilvanicum }\end{array}$ & $\begin{array}{c}\text { La mayoría simples, } \\
\text { algunas dobles }\end{array}$ & $\begin{array}{c}\text { Redondeadas a } \\
\text { subcuadradas }\end{array}$ & Deltoides & $900-4300$ \\
$\begin{array}{l}\text { P. perichaetiale } \\
\text { subsp. oligodus }\end{array}$ & Simples & Cuadradas & Deltoides & $3000-4300$ \\
$\begin{array}{l}\text { P. semipellucidum } \\
\text { P. tortile }\end{array}$ & Simples & Redondeadas & Liguladas & $1300-1800$ \\
\hline
\end{tabular}


A. Aponte-R. y J. Uribe-M. - Revisión de la familia Polytrichaceae para Colombia

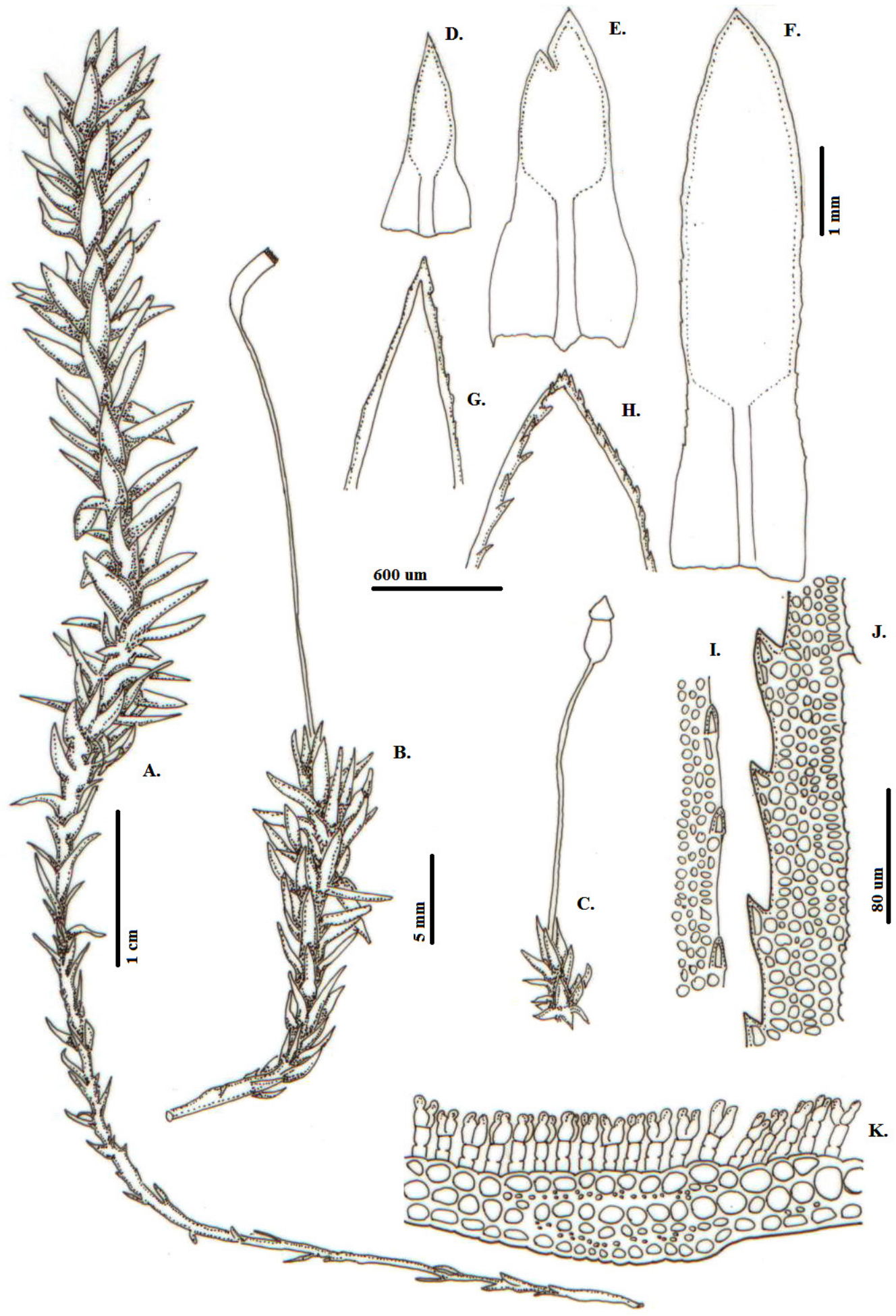

Fig. 5. Pogonatum campylocarpum (Müll. Hal.) Mitt. A-C. Hábito, D-F. Hoja, G-H. Detalle del ápice, I-J. Detalle del margen, K. Corte transversal. [A., de Churchill 18086, B. de Cleef 9279a, C, E y H. de Churchill 17228, D, G e I. de Cuatrecasas 8789, F, J y K. de Churchill 17263]. 
de $20-80$ x 8-10 $\mu \mathrm{m}$. Peristoma de 32 dientes, de 100-300 x 20-100 $\mu$ m. Caliptra mitrada, de hasta 5 $\mathrm{mm}$, parda o amarilla, pilosa.

Material estudiado. COLOMBIA. Dpto. Antioquia, Belmira, 641'N 7540'W, 2445-2935 m, 23-IV-91, Churchill 17794 (COL-HUA-NY); Dpto. Boyacá, Alto de Mogotes, 3180 m, 02-IV73, Cleef 3180 (COL); Dpto.Caquetá, Gabinete, 2300-2330 m, 27-III-40, Cuatrecasas 8789 (COL); Dpto. Cauca, Coconuco, $2^{\circ} 24^{\prime} \mathrm{N} 76^{\circ} 24^{\prime} \mathrm{W}, 3000$ m, 11-I-91, Churchill 17263 (COL-HUA-NY); Dpto. Chocó, Quibdó, 90 m, 19-XI-04, Pino 60 (COL); Dpto. Cundinamarca, Choachí, $3300 \mathrm{~m}$, 28-VIII-92, Linares 3927 (COL-HUA-NY); Dpto. Magdalena, Sierra Nevada de Santa Marta, 2800 m, 11-VIII-77, Rangel 852 (COL); Dpto. Nariño: Mallama, $1^{\circ} 10^{\prime} \mathrm{N} 77^{\circ} 51^{\prime} \mathrm{W}, 2300-2500 \mathrm{~m}, 17-$ X-93, Ramírez 5771 (COL-NY); Dpto. Norte de Santander, Toledo, 706'92'N 72'19'29'W, 2050 m, 25-I-95, Churchill 18883 (COL-NY); Dpto. Quindio, Armenia, 4²8'N 75³3'W, 3140 m, 10I-91, Churchill 17228 (COL-HUA-NY); Dpto. Tolima, Santa Isabel, 2640 m, 31-VII-80, Griffin III 42 (COL); Dpto. Valle del Cauca: El Cerrito, $3^{\circ} 45^{\prime} \mathrm{N} 76^{\circ} 05^{\prime} \mathrm{W}, 3500 \mathrm{~m}, 27-\mathrm{VI}-87$, Churchill 15357 (CUVC). BOLIVIA. Dpto. Santa Cruz, Vallegrande, $18^{\circ} 38^{\prime} \mathrm{S} 64^{\circ} 02^{\prime} \mathrm{W}, 2450 \mathrm{~m}, 27-\mathrm{II}-02$, Churchill 21177 (COL). COSTA RICA. Prov. San José, cordillera de Talamanca, 2387-2500 m, 11VII-61, Mora 1974 (COL).

Distribución geográfica. En Colombia se encuentra en los departamentos de Antioquia, Boyacá, Caquetá, Cauca, Chocó, Cundinamarca, Magdalena, Nariño, Norte de Santander, Quindío y Valle del Cauca entre 90-4350 m de altitud (Fig. 10). También ha sido reportada de Costa Rica, El Salvador, Panamá, República Dominicana (Hyvönen, 1989), Venezuela, Ecuador, Perú, Bolivia (Churchill et al., 2000), Argentina (Schiavone, 1978) y Brasil (Peralta \& Yano, 2010)

Hábitat. Común en suelo, barrancos y areniscas y sobre rocas, en zonas perturbadas e incluso cercanas a quebradas.

Observación. Se distingue fácilmente porque las células apicales de las lamelas son dobles, piriformes, lisas. Para Colombia (Churchill \&
Linares, 1995; Churchill, 2016) se habían registrado Pogonatum campylocarpum y P. neglectum, diferenciadas por el tamaño, la disposición de las hojas en el tallo y la dentición del margen del limbo y la vaina (Hyvönen, 1989). Luego de observar los ejemplares Tipo de dichas especies, se evidencia que la variación de los caracteres utilizados por Hyvönen (1989) no ofrecen suficiente soporte para considerarlas entidades diferentes, sino que en concordancia con la propuesta de Menzel (1985), $P$. neglectum y $P$. campylocarpum son conespecíficas. Se trata de una especie con amplia distribución geográfica, desde México hasta Argentina, en la que el tamaño del gametofito tiene un amplio rango de variación y la presencia de dientes sobre la vaina es un carácter inconstante e independiente del tamaño de la planta.

Pogonatum pensilvanicum (Bartram ex Hedw.) P. Beauv.

Pogonatum pensilvanicum (Bartram ex Hedw.) P. Beauv., Mém. Soc. Linn. Paris 1: 461. 1822. Polytrichum pensilvanicum Bartram ex Hedw., Sp. Musc. Frond. 96. pl. 21, f.1-6. 1801. Tipo: USA, Mühlenberg (Lectotipo designado por Hyvönen, 1989. BM!). Fig. 6

Pogonatum abbreviatum Mitt., J. Linn. Soc., Bot. 12: 615.1869. Tipo: Colombia, Weir 164 (NY 1834873!, 1834874!). Syn. Nov.

Plantas pequeñas de hasta $0,5 \mathrm{~cm}$ de longitud; verde claro. Protonema persistente, acintado, verde, de células alargadas. Tallo simple. Hojas de 1,5-4 x 0,5-1,5 mm; deltoides a lanceoladas; margen serrado; ápice agudo o acuminado terminando en dos dientes curvados; base de la hoja amplia, amarilla a verde amarillenta; nervio percurrente, espinoso en el envés; lamelas sobre el nervio; en sección transversal, 4-15 filas de lamelas discontinuas, de 3-5 células de alto, célula lamelar apical indiferenciada, redondeada a cuadrada, ocasionalmente geminada, de 8-20 $\mu \mathrm{m}$ de ancho. Células de la epidermis ventral de 5-15 x 4-15 $\mu \mathrm{m}$; células guía indiferenciadas, de 8-15 x 6-15 $\mu \mathrm{m}$; células de la epidermis dorsal de 6-10 x 5-20 $\mu \mathrm{m}$; células del limbo de 10-20 x 5-20 $\mu$ m; células de la base de $25-150 \times 8-20 \mu \mathrm{m}$.

Dioicas. Periquecio terminal; arquegonios abundantes; hojas periqueciales indiferenciadas; 


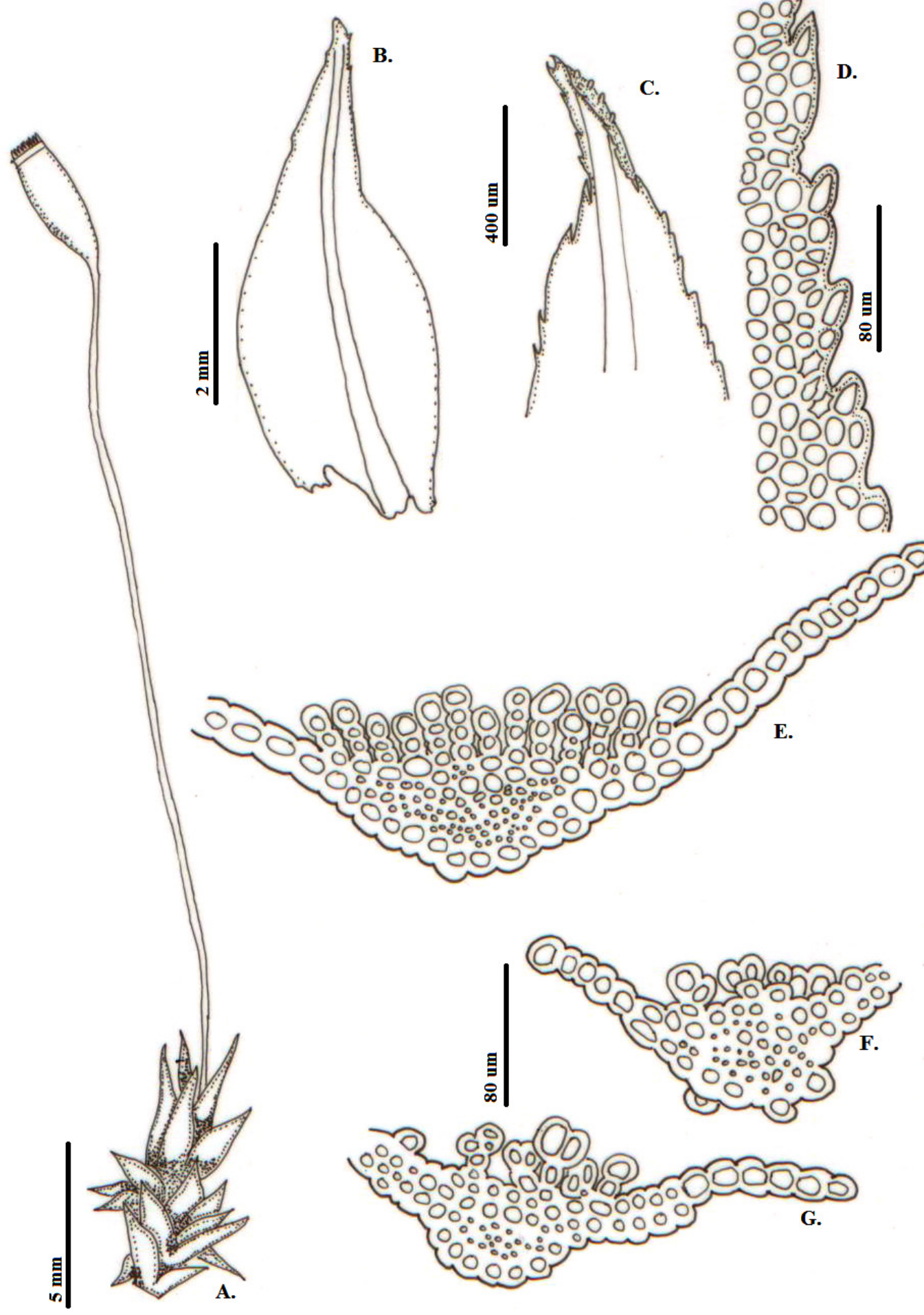

Fig. 6. Pogonatum pensilvanicum (Bartram ex Hedw.) Beauv. A. Hábito, B-G. Hoja, B. Vista general, C. Detalle del ápice, D. Detalle del margen, E. Corte transversal a la altura media de la hoja, F-G. Corte transversal a la altura del ápice. [Todas de Merrill King c860]. 
paráfisis filiformes, escasas. Perigonio no visto. Esporofito solitario. Seta lisa, roja, 1-2,5 cm de largo, recta o levemente sinuosa. Cápsula erecta, cilíndrica, de 1,5-2 $\mathrm{mm}$ de largo; células del exotecio de 20-35 x 10-25 $\mu \mathrm{m}$. Peristoma de 32 dientes, de 150-200 x 25-50 $\mu \mathrm{m}$. Caliptra mitrada, de hasta $5 \mathrm{~mm}$, amarilla, pilosa.

Material estudiado. COLOMBIA. Dpto.

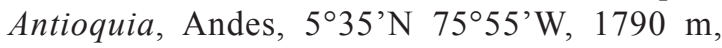
20-VII-86, Churchill 14580 (COL-HUA-NY); Dpto. Caquetá, San Vicente del Caguán, ${ }^{\circ} 46^{\prime} \mathrm{N}$ 7501'W, $1300 \mathrm{~m}, 25-X I-90$, Churchill 17047 (COL-NY). USA. Est. Illinois, 10-X-74, Zehr 13 (COL).

Distribución geográfica. En Colombia se encuentra en los departamentos de Antioquia, Caquetá y probablemente Sucre (Serranía del Perijá) (localidad del ejemplar Tipo de P. abbreviatum: "Andes Novo Granatenses, in declivibus ad viam inter Marta et Bucaramanga, 6000 ped. Weir 164") entre los 1300-1800 m de altitud (Fig. 10). También ha sido reportada para Canadá, Estados Unidos, México, Cuba, Bolivia, Perú, Brasil, Paraguay (Hyvonen, 1989) y Costa Rica (De Luna et al., 2002)

Hábitat. Es una especie poco colectada, común en los taludes y sitios arenosos. Crum \& Anderson (1981) afirmaron que se trataba de una especie pionera, en bordes de camino o barrancos arcillosos y que al parecer es acidófila.

Observación. Se distingue fácilmente por tratarse de plantas muy pequeñas, con protonema persistente.

Pogonatum perichaetiale (Mont.) Jaeger subsp. oligodus (Müll.Hal.) Hyvönen

Pogonatum perichaetiale (Mont.) Jaeger, Ber. S. Gall. Naturw. Ges. 257. 1875. Polytrichum perichaetiale Mont. Ann. Sci. Nat. Bot. 2(17): 252. 1842. Tipo: India, Perrotet 1622 (P 131639!, 131640!). Polytrichum oligodus Kunze ex Müll. Hal., Linnaea 18 :100. 1844, nom. nud.; Syn. Musc. Frond.1: 206. 1848. Pogonatum oligodus (Kunze ex Müll. Hal.) Mitt. J. Linn. Soc. 12: 613. 1869. Tipo: Chile, Poeppig 271 (Lectotipo designado por Hyvönen, 1989 BM, JE!). Fig. 7
Pogonatum jaffuelii Thér., Revista Chilena Hist. Nat. 33: 138.7 f.2. 1930. Tipo: Bolivia, Jaffuel 261 (P!)

Plantas pequeñas a medianas, de hasta $4 \mathrm{~cm}$ de long.; pardo a pardo rojizo. Tallo simple o ramificado. Hojas de 3,5-9 x 0,5-1,5 mm; deltoides; diferenciadas en vaina y limbo; limbo plano, de 2,5-8 $\mathrm{mm}$ de largo; margen leve a fuertemente serrado; ápice acuminado a largo acuminado; nervio percurrente, entero en el envés; lamelas sobre el nervio y parte de la lámina; en sección transversal, 20-40 filas, de 5-9 células de alto, célula lamelar apical cuadrada, lisa, de 20-35 $\mu \mathrm{m}$ de ancho. Células de la epidermis ventral de 5-15x 10-30 $\mu \mathrm{m}$; células de la epidermis dorsal de 10-25 x15-30 $\mu \mathrm{m}$; células del limbo de 10-35 x 5-35 $\mu \mathrm{m}$; células de la vaina de 20-100 x 5-35 $\mu$ m; células de la unión entre la vaina y el limbo de 3-20 x 10-40 $\mu \mathrm{m}$.

Monoicas o Dioicas. Gametoceo discoide; hojas periqueciales diferenciadas; paráfisis escasas; anteridios en la periferia; hojas perigoniales diferenciadas, 8-10 x 1-2 mm; paráfisis uniseriadas. Esporofito 1-4 en el mismo gametoceo. Seta lisa, roja, de 25-35 $\mathrm{mm}$ de largo. Cápsula erecta, cilíndrica, de 4,5-5 $\mathrm{mm}$ de largo, con costillas; células del exotecio de 60-70 x 10-20 $\mu \mathrm{m}$. Peristoma de 32 dientes de 250-300 x 50-100 $\mu$ m. Caliptra mitrada, de hasta $8 \mathrm{~mm}$, amarilla, pilosa.

Material estudiado. COLOMBIA. Dpto. Boyacá, Guicán-Cubará, 3900 m, 27-VII-85, Escobar 367 (COL-HUA-NY); Dpto. Cundinamarca, Usme, 3000-3100 m, 27-VI-50, Idrobo 422 (COL); Dpto. Magdalena, Sierra Nevada de Santa Marta, 4100 m, 28-I-67, Mägdefrau 1185 (COL); Dpto. Nariño: Pasto, $1^{\circ} 12^{\prime} \mathrm{N} 77^{\circ} 20^{\prime} \mathrm{W}, 3300$ m, 14I-91, Churchill 17419 (HUA-NY); Dpto. Valle del Cauca, Bugalagrande, 3100 m, 15-IV-1946, Cuatrecasas 20825 (COL). ECUADOR: Dpto. Cotopaxi, Páramo de Zumbagua, 4180 m, 17-VII59, Barclay 8129 (COL).

Distribución geográfica. En Colombia se encuentra en los departamentos de Boyacá, Cundinamarca, Magdalena, Nariño y Valle del Cauca entre 3000-4300 m de altitud (Fig. 10). También ha sido reportada de Venezuela, Ecuador, Perú y Bolivia (Churchill et al., 2000), Brasil 
A. Aponte-R. y J. Uribe-M. - Revisión de la familia Polytrichaceae para Colombia
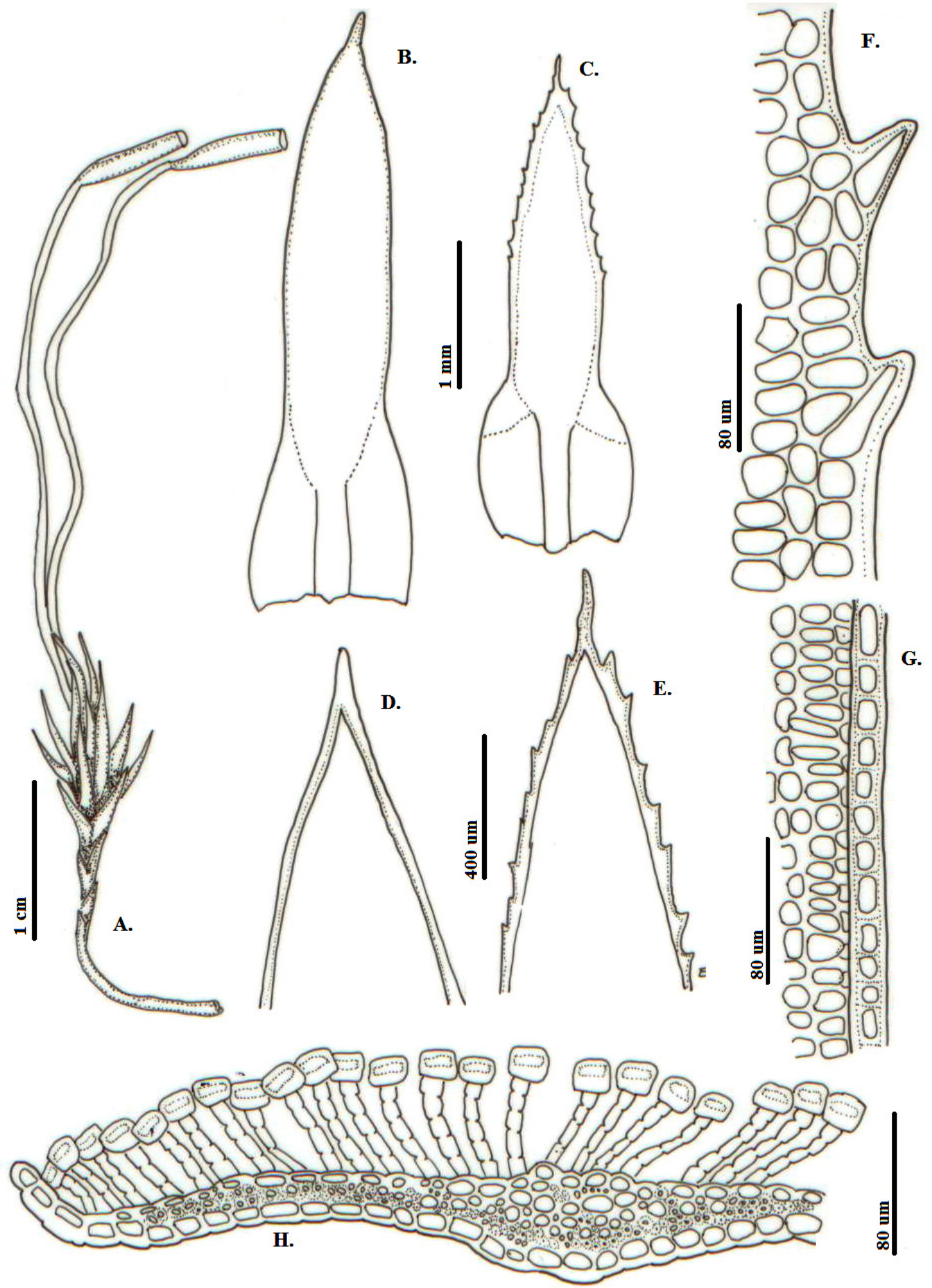

Fig. 7. Pogonatum perichaetiale subsp. oligodus (Müll. Hal.) Hyvönen: A. Hábito B-H. Hoja, B-C. Vista general (en $\mathrm{C}$ la zona punteada corresponde con la región de los hombros), D-E. Detalle del ápice, F-G. Detalle del margen, H. Corte transversal. [A, C, E, F y H, de Churchill 17419, B, D y G, de Mägdefrau 1185]. 
(Peralta \& Yano, 2010), África, Centroamérica -Guatemala, México y República Dominicana-, Argentina y Chile (Hyvönen, 1989)

Hábitat. Común sobre roca, en barrancos, en suelo, de ambientes muy húmedos o secos, expuestos.

Observación. Se distingue fácilmente por el ápice aristado, las células de la epidermis dorsal con lúmen muy amplio y células apicales de las lamelas cuadradas. Adicionalmente, en vista de que en el material examinado se encontraron ejemplares tanto con margen entero como serrado, se sigue a Hyvönen (1989) quien propuso la subespecie Pogonatum perichaetiale subsp. oligodus (Müll. Hal.) Hyvönen, que reúne la variación morfológica observada y está presente en África y América.

Pogonatum semipellucidum (Hampe) Mitt.

Pogonatum semipellucidum (Hampe) Mitt. J. Linn. Soc., Bot. 12: 617. 1869. Polytrichum semipellucidum Hampe, Linnaea 20: 80.1847. Tipo: Venezuela, Moritz 188 (BM 960698!, BM 960697!). Fig. 8

Plantas robustas de hasta $20 \mathrm{~cm}$ de longitud; verde intenso. Tallo simple. Hojas de 5-14 x 1-3 mm; liguladas a lineares; margen plano, fuertemente serrado, dientes formados por varias células, células del margen isodiamétricas; ápice agudo; base de la hoja levemente amplectante; verde amarillenta; nervio robusto, percurrente, espinoso en el envés; lamelas sobre el nervio y parte de la lámina; en sección transversal, 20-44 filas de lamelas de 1 célula de alto, redondeadas, de pared delgada, lisa de 5-25 $\mu \mathrm{m}$ de ancho. Células de la epidermis ventral de 5-20 x 15-30 $\mu$ m; células de la epidermis dorsal de 2-20 x 5-20 $\mu$ m; células del limbo de 10-30 x 10-30 $\mu \mathrm{m}$; células de la base de $50-150 \times 10-30 \mu \mathrm{m}$.

Dioicas. Periquecio terminal; arquegonios escasos; hojas periqueciales diferenciadas, liguladas a acintadas, de 10-15 x 2-3 mm, margen serrado, ápice agudo, paráfisis filiformes, escasas. Perigonio terminal; anteridios abundantes; hojas perigoniales diferenciadas, lanceoladas a orbiculares, de 2,5-6 x 2-5 mm, ápice agudo, margen y envés fuertemente serrado; paráfisis filiformes, abundantes. Esporofito solitario. Seta lisa, roja, 3-4 cm de largo, recta. Cápsula cilíndrica, contraída debajo del peristoma, erecta, 5-7 $\mathrm{mm}$ de largo, con costillas evidentes; células del exotecio de 30-40 x 10-20 $\mu \mathrm{m}$. Peristoma de 32 dientes, de 400-450 x 100-125 $\mu \mathrm{m}$. Caliptra mitrada, de hasta $8 \mathrm{~mm}$, amarilla, pilosa.

Material estudiado. COLOMBIA. Dpto. Antioquia, La Estrella, 68' $\mathrm{N} 75^{\circ} 38^{\prime} \mathrm{W}, 2250-2550$ m, 10-VIII-92, Churchill 18500 (COL-HUA-NY); Dpto. Cundinamarca: Andes de Bogotá. Cincha, 2200 m, XI- 1856, Triana 1492 (COL); Dpto. Huila, Venadito, 2400 m, 28-XI-44, Little 9005 (COL); Dpto. Magdalena, Santa Marta, 2400 m, 03-VIII-46, Foster 1367 (COL); Dpto. Nariño, Ipiales, 1³9’ N 77³4’W, 2400-2600 m, 18-IV-95, Ramírez 7333 (COL-NY); Dpto. Risaralda, Santa Rosa de Cabal, 2700 m, 17-VII-80, Van Reenen 1409 (COL); Dpto. Santander, Onzaga, 2640 m, 30-III-76, Torres 555 (COL).VENEZUELA: Est. Mérida, Sierra Nevada. 2300 m, 20-VI-72, Cleef 4814 (COL).

Distribución geográfica. En Colombia se encuentra en los departamentos de Antioquia, Cundinamarca, Huila, Magdalena, Nariño, Risaralda, Santander y Valle del Cauca entre 1150-3200 m de altitud (Fig. 10). También ha sido reportada de Venezuela, Ecuador y Perú (Churchill et al., 2000) y Bolivia (Menzel, 1987; Hyvönen, 1989)

Hábitat. Común en barrancos, sobre el suelo o epífita sobre troncos en descomposición, es una especie frecuente en los bosques intervenidos, sobre humus hasta terreno arcilloso, en ambientes húmedos y preferiblemente en ambientes sombreados.

Observación. Pogonatum semipellucidum se caracteriza por las hojas largas, laxas, verde brillante, y las lamelas con una célula de alto.

Pogonatum tortile (Sw.) Brid.

Pogonatum tortile (Sw.) Brid., Bryol. Univ. 2: 108. 1827. Polytrichum tortile Sw. J. Bot. (Schrader) 1800 (2): 175.1801. Tipo: Jamaica. (BM 960657!). Fig. 9

Plantas pequeñas a medianas de hasta $4 \mathrm{~cm}$ de long; verde claro u oscuro. Tallo simple. Hojas 


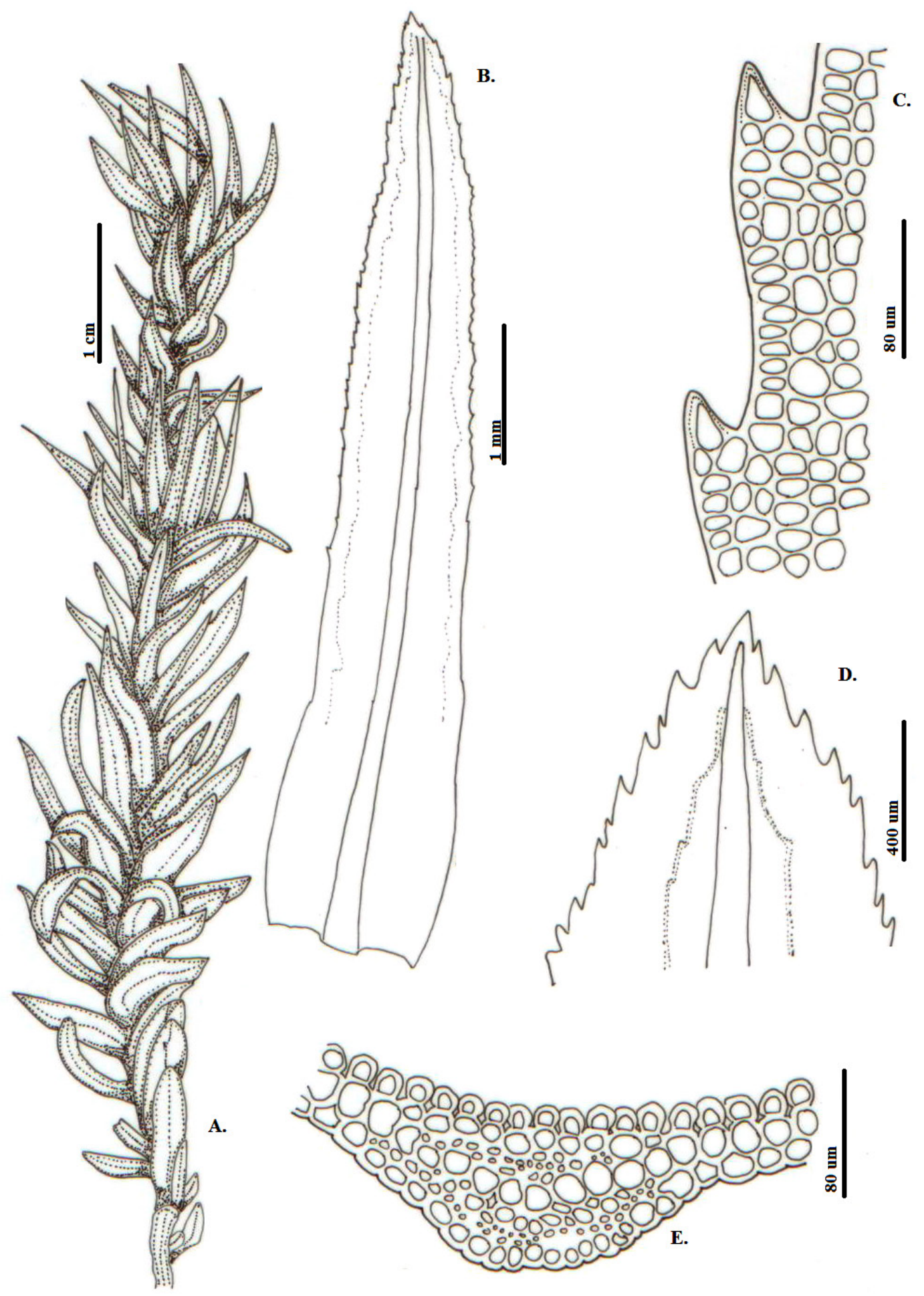

Fig. 8. Pogonatum semipellucidum (Hampe) Mitt., A. Hábito, B-E. Hoja, B. Vista general, C. Detalle del margen, D. Detalle del ápice, E. Corte transversal. [A., de Churchill 15114, B., C., D., y E. de Prieto 597]. 
Bol. Soc. Argent. Bot. 52 (2) 2017

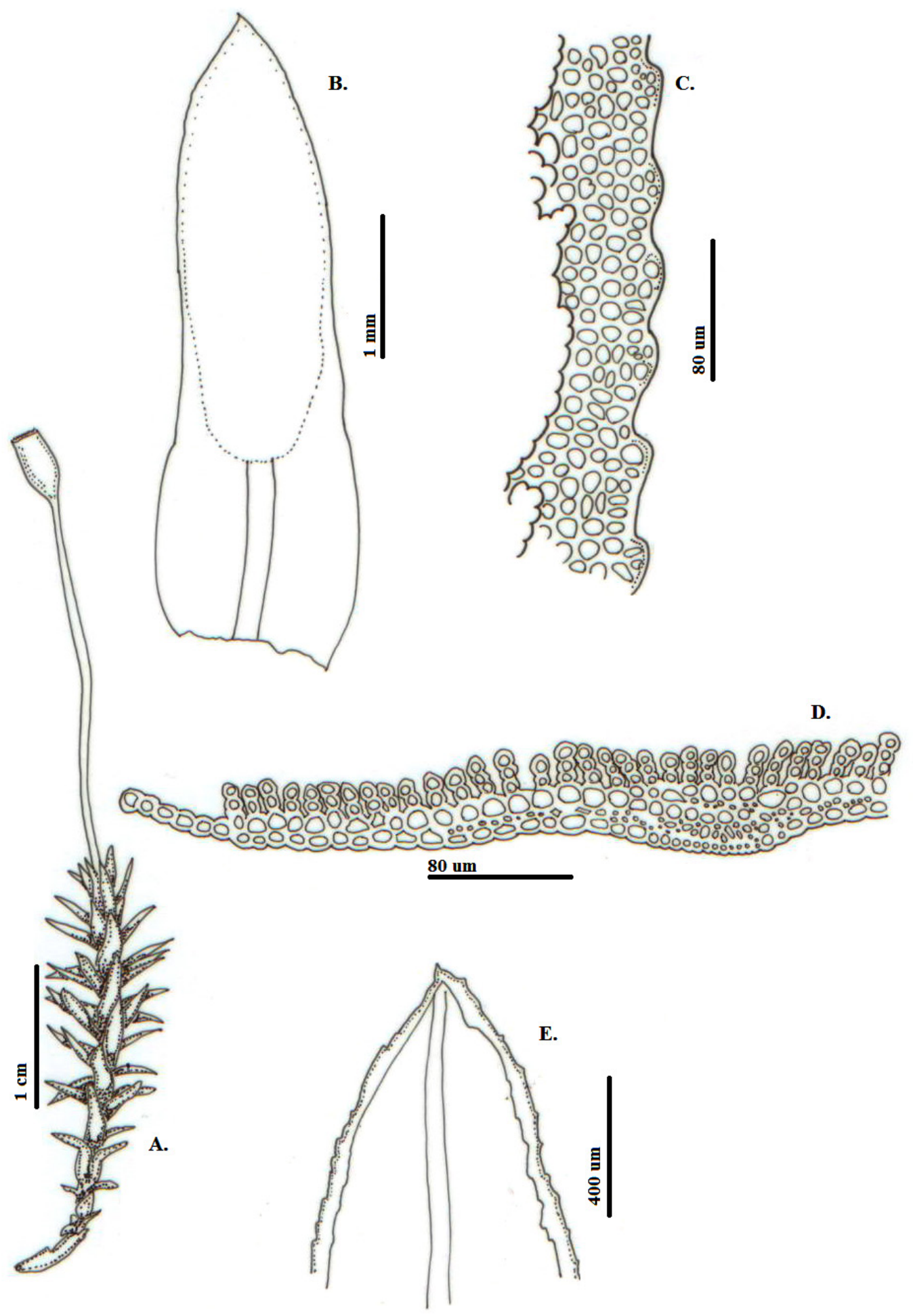

Fig. 9. Pogonatum tortile (Sw.) Brid.: A. Hábito, B-E. Hoja, B. Vista general, C. Detalle del margen, D. Corte transversal, E. Detalle del ápice. [A., de Philipson \& Idrobo 1812, B., C., D., y E. de Churchill 14319]. 
de 2,5-6 x 0,5-1,5 mm; deltoides a triangulares; diferenciadas en vaina y limbo; limbo de $2-4 \mathrm{~mm}$ de largo; margen serrado; ápice agudo; vaina levemente amplectante al tallo, amarilla a verde; nervio fuerte, rojizo, percurrente, espinoso en el envés; lamelas sobre el nervio y parte de la lámina; en sección transversal, 27-50 filas de lamelas, 3-4 células de alto, célula lamelar apical redondeada, ocasionalmente geminada, lisa, de 10-20 $\mu \mathrm{m}$ de ancho. Células de la epidermis ventral de 5-20 x 10-20 $\mu \mathrm{m}$; células guía de 5-20 x 10-20 $\mu \mathrm{m}$; células de la epidermis dorsal de 2-10 x 3-15 $\mu \mathrm{m}$, con espinas en la superficie abaxial del nervio; células del limbo de 5-15 x 10-15 $\mu$ m; células de la vaina de 15-100 x 10-20 $\mu \mathrm{m}$; células de la unión entre la vaina y el limbo de 5-20 x 10-25 $\mu \mathrm{m}$.

Dioicas. Periquecio terminal; arquegonios escasos; hojas periqueciales diferenciadas, deltoides, 4-6 x 1-2 mm, ápice agudo, margen serrado; paráfisis filiformes, escasas. Perigonio terminal; anteridios abundantes, cilíndricos, de 1-1,5 mm de largo; hojas perigoniales diferenciadas, lanceoladas a orbiculares, de 1-5 x 1-5 mm, ápice agudo, margen serrado; paráfisis filiformes, escasas. Esporofito solitario. Seta lisa, roja, 1,5-2,5 $\mathrm{cm}$ de largo, recta. Cápsula cilíndrica, erecta o levemente inclinada, 3,5-5 mm de largo; células del exotecio de 30-60 x 10$40 \mu \mathrm{m}$. Peristoma de 32 dientes de $60 \times 15-25 \mu \mathrm{m}$. Caliptra no vista.

Material estudiado. COLOMBIA. Dpto. Antioquia, Barbosa, $6^{\circ} 25^{\prime} \mathrm{N} 75^{\circ} 15^{\prime} \mathrm{W}, 1300$ m, 13-VII-86, Churchill 14319 (COL-HUANY); Dpto. Caquetá, Belén de los Andaquíes, 140'58" N, 7554'21" W, 1100-1400 m, 23-VII11, Cárdenas 41823 (COAH); Dpto. Meta, La
Macarena, 1700 m, I-51, Schultes 11223 (COL); Dpto. Risaralda, Marsella, 1500 m, 25-VII-80, Aguirre 1477 (COL)

Distribución geográfica. En Colombia se encuentra en los departamentos de Antioquia, Caquetá, Meta y Risaralda, entre 800 y 1700 m de altitud (Fig. 10). También ha sido reportada de Costa Rica, Guatemala, México, Nicaragua, Panamá, Cuba, República Dominicana, Guadalupe, Jamaica, Martinica, Puerto Rico, Trinidad, Bolivia, Ecuador, Perú y Venezuela (Hyvönen, 1989; Churchill et al., 2000)

Hábitat. Común en barrancos, rocas y epífita en corteza de árbol.

Observación. Se distingue por el margen de la hoja irregularmente serrado y por la forma de las células apicales de las lamelas, que en un mismo corte pueden ser redondeadas, o piriformes, simples o geminadas. Hyvonen (1989) resaltó la cantidad de nombres dados a la especie, a pesar de no tener una amplia variabilidad morfológica.

Polytrichadelphus (Mull. Hal.) Mitt.

Polytrichadelphus (Müll. Hal.) Mitt., J. Proc. Linn. Soc., Bot. 4: 97. 1859.

Catharinea sect. Polytrichadelphus Müll. Hal. Syn. Musc. Frond.1: 201. 1848.

Tipo: Polytrichum magellanicum Hedw., Sp. Musc. Frond. 101. 20. f. 1-2. 1801. [= Polytrichadelphus magellanicus (Hedw.) Mitt. ]

Las principales características que distinguen a las especies de Polytrichadelphus se presentan en la Tabla 2.

Tabla 2. Comparación entre algunas características de las especies de Polytrichadelphus presentes en Colombia.

\begin{tabular}{|llllll|}
\hline \multicolumn{1}{|c}{ Especies } & Margen del limbo & Forma del ápice del limbo & Superficie abaxial del limbo & Altitud \\
\hline P. ciliatus & Ciliado & Acudo a corto acuminado & Entero & $2750-3500$ \\
P. giganteus & $\begin{array}{l}\text { Serrado } \\
\text { P. longisetus }\end{array}$ & $\begin{array}{l}\text { Entero a fuermente } \\
\text { serrado }\end{array}$ & $\begin{array}{l}\text { Agudo, apiculado a } \\
\text { largo aristado }\end{array}$ & Escabroso a fuertemente serrado & $3000-4300$ \\
\hline
\end{tabular}


Bol. Soc. Argent. Bot. 52 (2) 2017

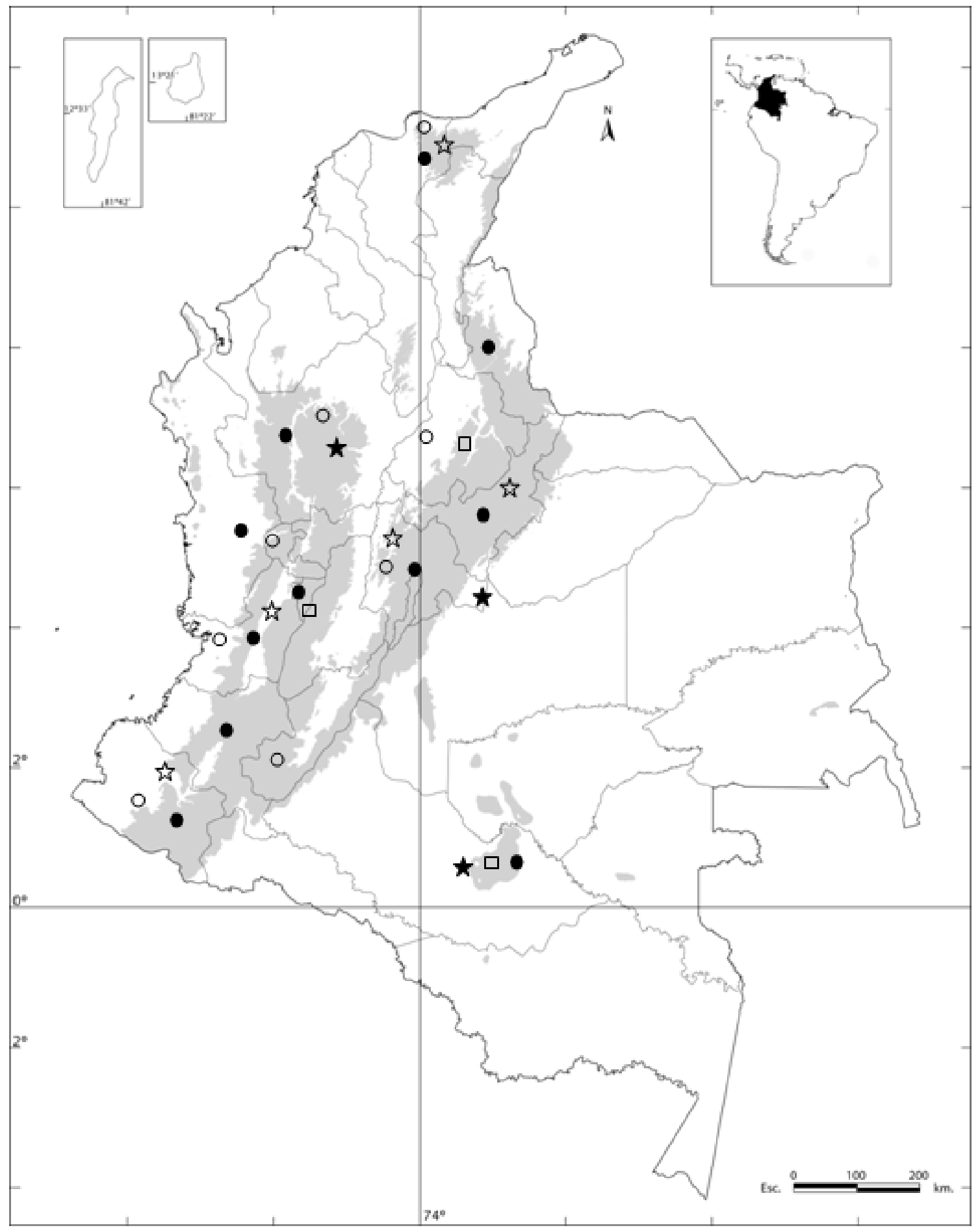

Fig. 10. Distribución geográfica departamental de Pogonatum en Colombia: ( $P$. campylocarpum $(\bullet), P$. oligodus (estrella blanca), P. pensilvanicum ( $\square$ ), P. semipellucidum (○) y P. tortile (estrella negra). 


\section{A. Aponte-R. y J. Uribe-M. - Revisión de la familia Polytrichaceae para Colombia}

\section{Clave para las especies colombianas de Polytrichadelphus}

1. Margen del limbo ciliado. P. ciliatus

1'. Margen del limbo entero o serrado. 2

2. Superficie abaxial del limbo escabrosa o espinosa, margen del limbo dentado solo en el tercio apical. P. giganteus

2'. Superficie abaxial del limbo generalmente lisa o con unos escasos dientes cerca del ápice, margen del limbo entero o serrado. P. longisetus

Polytrichadelphus ciliatus (Hook. \& Wilson) Mitt. Polytrichadelphus ciliatus (Hook. \& Wilson) Mitt., J. Linn. Soc., Bot. 12: 608. 1869. Polytrichum ciliatum Hook \& Wilson, London J. Bot. 6: 290.10.1847. Tipo: Colombia, Purdie s.n. (BM 960573!, 960574!). Fig.11

Plantas grandes de hasta $25 \mathrm{~cm}$ de longitud; verde oscuro a pardo. Tallo simple. Hojas de 6-9 $\mathrm{mm}$ de largo, 0,5-1,5 mm de ancho en la zona media y 1,52,5 mm de ancho en la base; deltoides; diferenciadas en vaina y limbo; limbo plano, multiestratificado de 4-6 mm de largo; margen ciliado; cilios hialinos 100 $-400 \mu \mathrm{m}$, dispuestos irregularmente, unicelulares; ápice agudo o acuminado; vaina amplectante, parcialmente anaranjada; nervio fuerte, percurrente o corto excurrente, entero en el envés; lamelas sobre el nervio y parte de la lámina; en sección transversal, 40-55 filas de lamelas, 6 células de alto, célula lamelar apical diferenciada, piriforme, lisa, 8-15 $\mu \mathrm{m}$ de ancho. Células de la epidermis ventral de 1-10 x 6-10 $\mu \mathrm{m}$; células guía de 4-10 x 6-15 $\mu \mathrm{m}$; células de la epidermis dorsal de 2-5 x 5-15 $\mu$ m; células del limbo de 10-35 x 5-15 $\mu \mathrm{m}$; células de la vaina de 20-90 x 5-20 $\mu \mathrm{m}$; células de los hombros de 3-10 x $5-20 \mu \mathrm{m}$.

Dioicas. Periquecio axilar; arquegonios abundantes; hojas periqueciales diferenciadas, 5-9 x 1-2,5 mm, ápice agudo o largo aristado, margen ciliado, cilios pequeños; paráfisis filiformes, escasas. Perigonio terminal; anteridios abundantes, cilíndricos, 1-2 $\mathrm{mm}$ de largo; hojas perigoniales diferenciadas, lanceoladas, orbiculares u ovadas, 5-10 x 1,5-4 mm, ápice agudo, margen ciliado; paráfisis clavadas, abundantes. Esporofito solitario. Seta lisa, roja o pardo, 3-6 cm de largo, recta. Cápsula bi-angulada, horizontal, de 5-7 $\mathrm{mm}$ de largo; células del exotecio de 15-35 x 15-25 $\mu \mathrm{m}$, con estomas en la base de la cápsula, inmersos, de 50-65 x 50-70 $\mu \mathrm{m}$. Peristoma de 64 dientes, de 150-250 x 50-100 $\mu \mathrm{m}$. Caliptra cuculada, de hasta $7 \mathrm{~mm}$, anaranjada o parda, glabra con espinas en el ápice.

Distribución geográfica. En Colombia se encuentra en los departamentos de Antioquia, Caldas, Cauca, Nariño, Quindío, Tolima y Valle del Cauca entre los 2400 y 3500 m (Fig. 14). También ha sido reportada de Venezuela y Ecuador (Churchill, 2000).

Hábitat. Se encuentra comúnmente en suelo, en barrancos y en orillas de carreteras. En sitios expuestos y secos o húmedos y sombríos. Desde el bosque montano alto hasta el páramo.

Observación. Es una especie fácilmente reconocible por los cilios hialinos en el margen del limbo. Polytrichum ciliatum fue descrito por Hooker (1847), en su publicación sobre los nuevos musgos de la Nueva Granada a partir de las colecciones que hizo Purdie y en donde se describió como una especie singular por sus hojas apiñadas, erectas y ciliadas.

Material estudiado. COLOMBIA. Dpto. Antioquia: Jardín, 5 532’N 7544’W, 2900 m, 04X-87, Churchill 15738 (COL-HUA-NY); Dpto. Caldas, Nevado del Ruíz, 3050 m, 15-VII- 1965, Merrill King 872 (COL); Dpto. Cauca, Totoro, $2^{\circ} 29^{\prime} \mathrm{N} 76^{\circ} 23^{\prime} \mathrm{W}, 3020 \mathrm{~m}, 11-\mathrm{V}-91$, Churchill 18001 (COL-HUA-NY); Dpto. Nariño, Pasto, $1^{\circ} 12^{\prime} \mathrm{N} 77^{\circ} 12^{\prime} \mathrm{W}, 3100 \mathrm{~m}, 5-\mathrm{XI}-1988$, Churchill 15919 (COL-HUA-NY); Dpto. Quindio, Armenia, $4^{\circ} 28^{\prime} \mathrm{N} 75^{\circ} 33^{\prime} \mathrm{W}, 3140 \mathrm{~m}, 10-\mathrm{I}-91$, Churchill 17195 (COL-HUA-NY); Dpto. Tolima, Cajamarca, 3200 m, 21-VII-66, Echeverry 1333 (COL); Dpto. Valle del Cauca, El Cerrito, $3^{\circ} 45^{\prime} \mathrm{N} 76^{\circ} 05^{\prime} \mathrm{W}, 3500 \mathrm{~m}$, 27-VI-87, Churchill 15359(COL-CUVC-HUANY). VENEZUELA. Est. Mérida, Rivas Dávila, $8^{\circ} 11^{\prime} \mathrm{N}, 71^{\circ} 55^{\prime} \mathrm{W}, 2830 \mathrm{~m}, 15-\mathrm{IV}-84$, Luteyn 9930 (NY).

Polytrichadelphus giganteus (Hook.) Mitt.

Polytrichadelphus giganteus (Hook.) Mitt., J. Linn. Soc., Bot. 12: 609. 1869. Polytrichum giganteum Hook., Musci Exot. 1: 63. 1818. Tipo: Colombia, Humboldt et Bonpland 52 (P 131378!, 
Bol. Soc. Argent. Bot. 52 (2) 2017

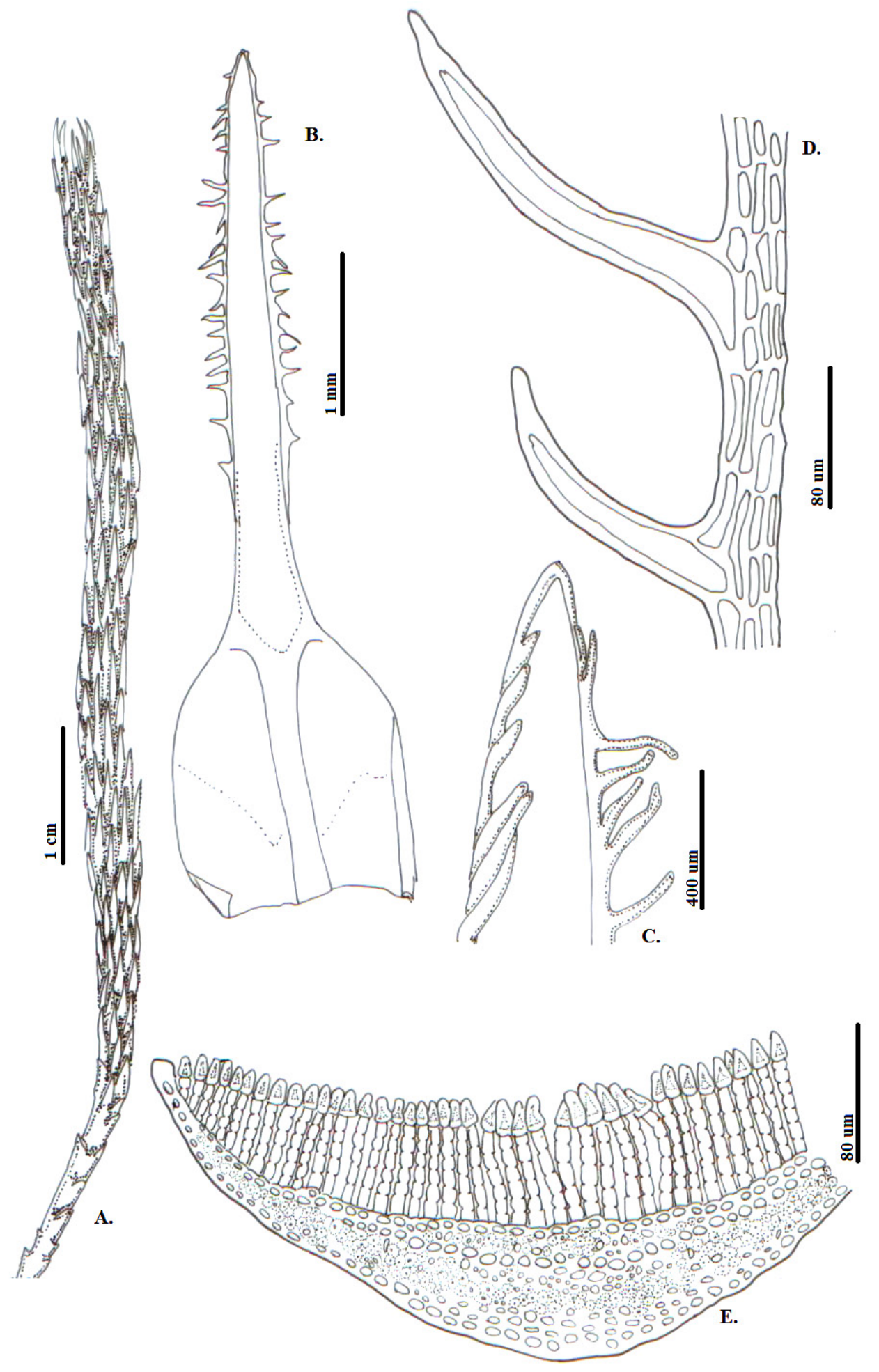

Fig. 11. Polytrichadelphus ciliatus (Hook.f. \& Wilson) Mitt.: A. Hábito, B-E. Hoja, B. Vista general, C. Detalle del ápice, D. Detalle del margen, E. Corte transversal. [Todas de Sipman 34216]. 
131375!, 131376!, 131377!, 131379!, 131380! у 131381!). Fig. 12

Polytrichadelphus purpureus Mitt., J. Linn. Soc., Bot. 12: 610.1869. Tipo: Ecuador, Jameson (NY 1408276). Syn. Nov.

Polytrichum rubescens Mitt. J. Linn. Soc., Bot. 12: 622. 1869. Polytrichadelphus rubescens (Mitt.) G.L. Smith., Phytologia 18: 403. 1969. Tipo: Ecuador, Jameson (NY 913045!, 913046! y P 131213!). Syn. Nov.

Plantas grandes de hasta $35 \mathrm{~cm}$ de longitud; pardo rojizo oscuro a pardas. Tallo simple o ramificado. Hojas 6-10 $\mathrm{mm}$ de largo, 0,5-1,5 mm de ancho en la zona media y 1,5-3 $\mathrm{mm}$ de ancho en la base; deltoides; diferenciadas en vaina y limbo; limbo plano, multiestratificado, 4-7 mm de largo; margen involuto o erecto, serrado; ápice agudo o largo acuminado; vaina amplectante, parcial a totalmente anaranjada; nervio fuerte, excurrente, escabroso a fuertemente espinoso en el envés; lamelas sobre el nervio y parte de la lámina, en sección transversal, 33-59 filas de lamelas, 6-9 células de alto, célula lamelar apical diferenciada piriforme, lisa, de 8-10 $\mu \mathrm{m}$ de ancho. Células de la epidermis ventral de 3-10 x 5-15 $\mu$ m; células guía de 4-10 x 8-15 $\mu \mathrm{m}$; células de la epidermis dorsal de

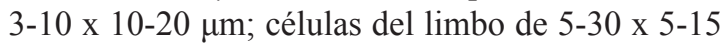
$\mu \mathrm{m}$; células de la vaina $60-150 \times 5-15 \mu \mathrm{m}$; células de los hombros de 2-15 x 10-25 $\mu \mathrm{m}$.

Dioicas. Periquecio terminal; arquegonios abundantes, 0,8-3 $\mathrm{mm}$ de largo; hojas periqueciales poco diferenciadas, 5-12 × 1-3 mm, ápice agudo a aristado, margen entero; paráfisis filiformes, escasas. Perigonio terminal; anteridios abundantes, cilíndricos, 1-3 mm de largo; hojas perigoniales diferenciadas, lanceoladas a orbiculares, 3-10 x 2-5 $\mathrm{mm}$, ápice agudo, margen entero; paráfisis clavadas, abundantes. Esporofito solitario. Seta lisa, roja o parda, 2-6 cm de largo, recta. Cápsula bi-angulada, 4-6 mm de largo; células del exotecio 15-40 x 15$30 \mu \mathrm{m}$, estomas en la base de la cápsula. Peristoma de 64 dientes, de 150-900 x 35-80 $\mu$ m. Caliptra cuculada, hasta $10,5 \mathrm{~mm}$, parda o anaranjada, con espinas en el ápice.

Material estudiado. COLOMBIA. Dpto. Caldas, Villamaría, $4^{\circ} 56^{\prime} \mathrm{N} 75^{\circ} 21^{\prime} \mathrm{W}, 3900 \mathrm{~m}, 11$ -
IV-90, Churchill 16296 (COL-NY); Dpto. Cauca, Inza, $2^{\circ} 28^{\prime} \mathrm{N} 76^{\circ} 15^{\prime} \mathrm{W}, 3240 \mathrm{~m}, 11-\mathrm{V}-91$, Churchill 18040 (COL-HUA-NY); Dpto. Cundinamarca, Páramo de Cruz Verde, 3500 m, 23-IV-72, Cleef 3133 (COL-NY); Dpto. Nariño, Pasto, $1^{\circ} 11^{\prime} \mathrm{N}$ 77²1'W, 3000 m, 14-IX-90, Ramírez 2679 (COLNY); Dpto. Putumayo, El Encano, 3250 m, 04-I41, Cuatrecasas 11747 (COL); Dpto. Risaralda, Santa Rosa, 3700 m, 17-IX-84, Aguirre 4953 (COL); Dpto. Tolima, Nevado del Tolima, 3500 m, 12-VIII-75, Van der Hammen 3304 (COLNY); Dpto. Valle del Cauca, El Cerrito, $3^{\circ} 45^{\prime} \mathrm{N}$ 7605'W, $3500 \mathrm{~m}, 27-\mathrm{VI}-87$, Churchill 15355 (COL-CUVC-HUA). ECUADOR. Prov. Carchi, Páramos del Angel, 3720 m, 22-VIII-57, Barclay 9366 (COL); Prov. Morona-Santiago, Páramo de Matanga, $3^{\circ} 11^{\prime} \mathrm{S} 78^{\circ} 47^{\prime} \mathrm{W}, 3300 \mathrm{~m}, 14-\mathrm{XII}-$ 80, Holm-Nielsen 29385 (COL); Prov. Napo, Cordillera de los Llanganates, 4100 m, 09-XI-80, Holm-Nielsen 28220 (COL); Prov. Pichincha, Volcán Atacazo, $0^{\circ} 20^{\prime} \mathrm{N} 78^{\circ} 37^{\prime} \mathrm{W}, 2800 \mathrm{~m}, 20$ VIII-80, Holm-Nielsen 25067 (COL).

Distribución geográfica. En Colombia se encuentra en los departamentos de Caldas, Cauca, Cundinamarca, Huila, Nariño, Putumayo, Risaralda, Tolima y Valle del Cauca entre 3000 y $4300 \mathrm{~m}$ de altitud (Fig. 14). También ha sido reportada de Bolivia, Ecuador (Churchill et al., 2000)

Hábitat. Común desde el bosque alto andino hasta el páramo, muy frecuente en barrancos, zonas abiertas y perturbadas, creciendo en suelo, arenisca o roca. En sitios soleados, secos o húmedos.

Observación. Se distingue por la superficie abaxial de limbo que es desde escabrosa hasta fuertemente serrada; el margen es serrado, aunque puede tener dientes solamente en el tercio apical o en los 2/3 del limbo; el ápice puede ser agudo hasta largo apiculado en las hojas más próximas al ápice de la planta.

Polytrichadelphus longisetus (Brid) Mitt.

Polytrichadelphus longisetus (Brid.) Mitt., J. Linn. Soc., Bot.12: 611.1869. Pogonatum longisetum Brid., Bryol. Univ. 2: 128.1827., Tipo: Colombia. Humboldt et Bonpland 25 (BM 1087579!, 1087577!,, 1087578!, 1087580!, NY 1408271 ! y 1408272 !). Fig. 13 
Bol. Soc. Argent. Bot. 52 (2) 2017
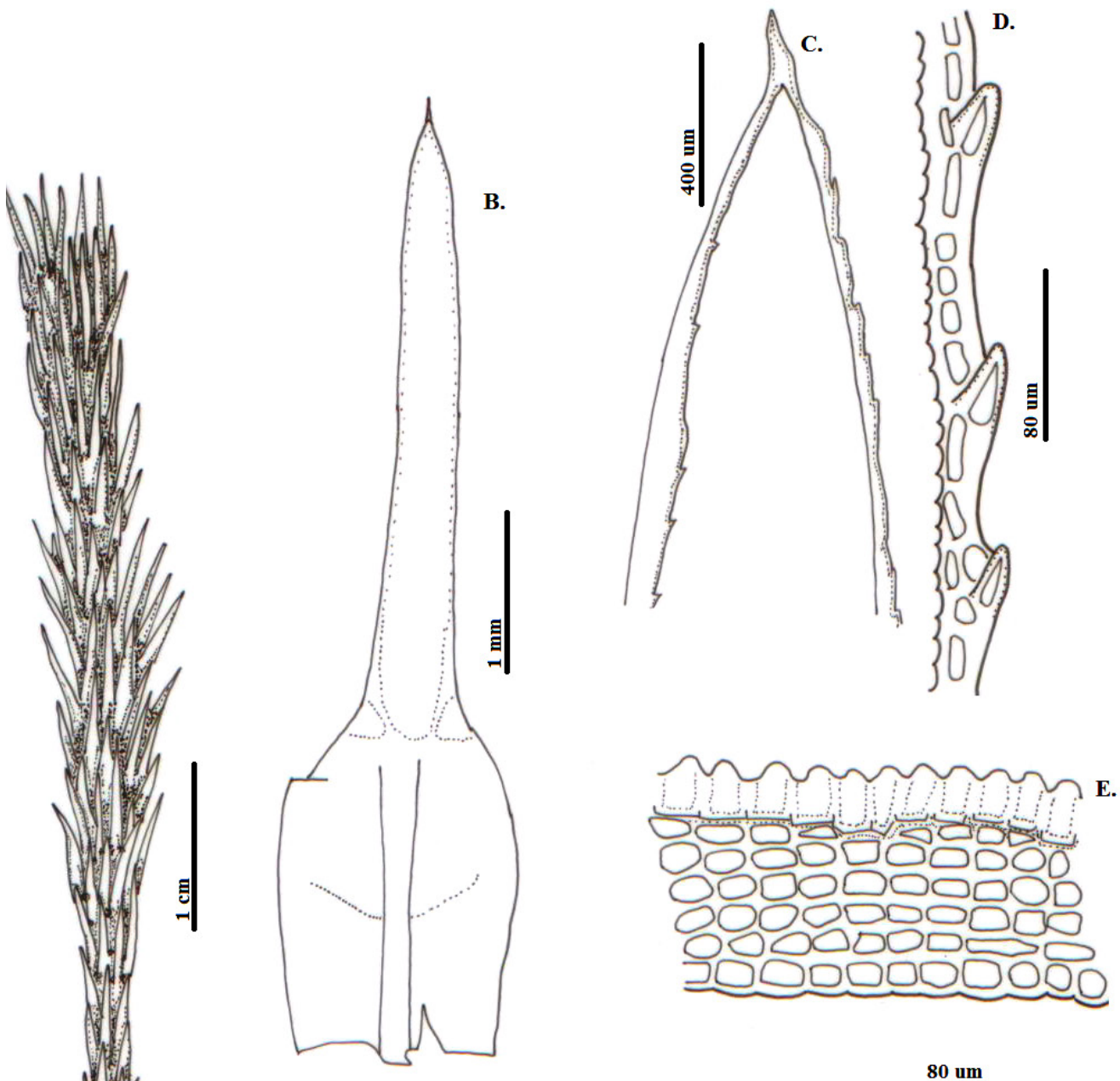

$80 \mathrm{um}$

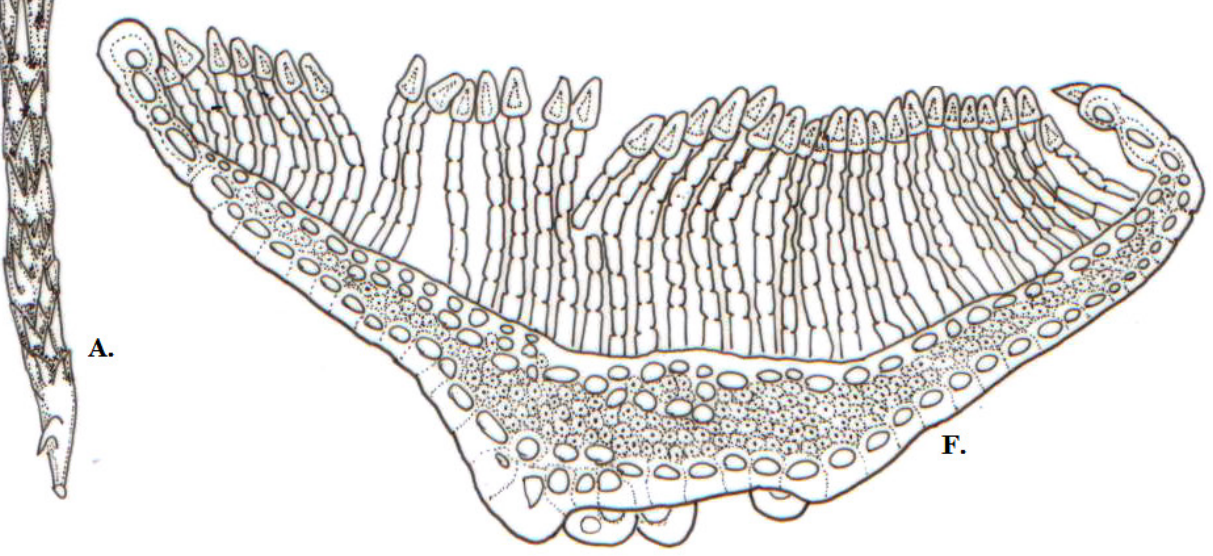

Fig. 12. Polytrichadelphus giganteus (Hook.) Mitt.: A. Hábito, B-F. Hoja, B. Vista general, C. Detalle del ápice, D. Detalle del margen, E. Vista lateral de las lamelas, F. Corte transversal [A. de Cardona 1049, B., C., D., E., y F. de Aguirre 4953]. 
A. Aponte-R. y J. Uribe-M. - Revisión de la familia Polytrichaceae para Colombia
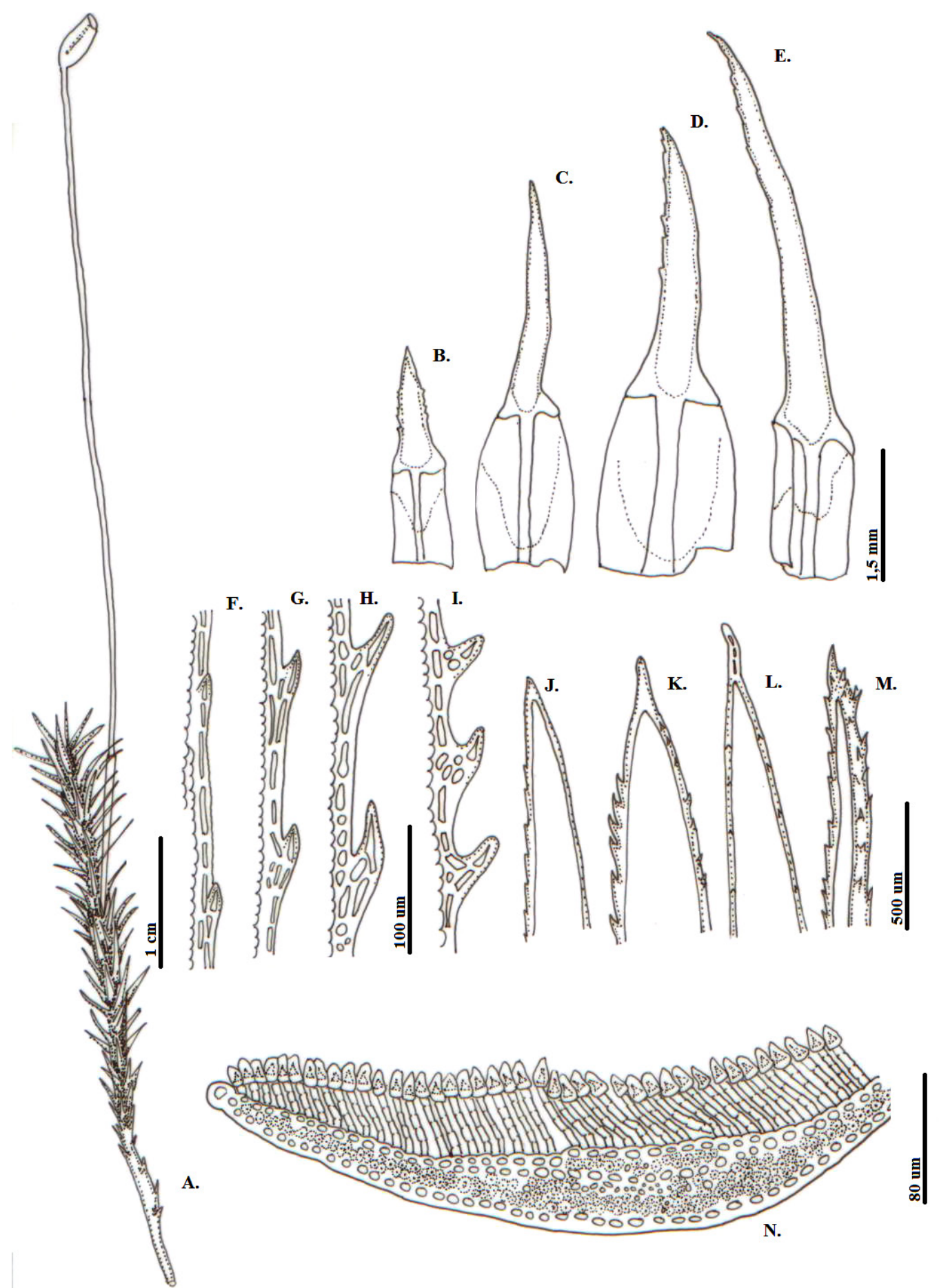

Fig. 13. Polytrichadelphus longisetus (Brid.) Mitt.: A. Hábito, B-N. Hoja, B-E. Vista general, F-I. Detalle del margen, J-M. Detalle del ápice, N. Corte transversal [A, C, G, L. y N. de Churchill 15059, B, I y K, de Echeverry 94, D, F y J, de Cuatrecasas 8788, E, H y M, de Aguirre 2062]. 
Polytrichum longisetum Hook., Musci Exot. 1: 66. 1818, nom. illeg.

Polytrichadelphus trianae (Müll. Hal.) Mitt., J. Linn. Soc., Bot. 12: 611. 1869. Catharinea trianae (Müll. Hal.) Hampe, Ann. Sci. Nat., Bot., sér. 5, 4: 346. 1865. Polytrichum trianae Müll. Hal., Bot. Zeitung (Berlin) 15: 577. 1857. Tipo: Colombia, Triana s.n. (BM 960607!)

Polytrichadelphus aristatus (Hampe) Mitt. J. Linn. Soc., Bot. 12: 609. 1869. Catharinea aristata Hampe, Linnaea 32: 146. 1863. Tipo: Colombia, Lindig 2002 (BM 960580!, 960578! y 960579!). Syn. Nov.

Polytrichadelphus rubiginosus Mitt., J. Linn. Soc., Bot. 12: 610. 1869. Tipo: Colombia, Weir 211 (NY 1835255!, 1835256!, 1835257!, BM 960559! y 960560 !). Syn. Nov.

Polytrichadelphus umbrosus Mitt., J. Linn. Soc., Bot. 12: 610. 1869. Tipo: Chile-Perú, Lechler 2205 (P 131387!). Syn. Nov.

Polytrichadelphus abriaquiae (Müll. Hal.) Jaeger, Ber. S. Gall. Naturw. Ges.1877-78: 453. 1880. Catharinea abriaquiae Müll. Hal. Flora 58: 534. 1875. Tipo: Colombia, Wallis s.n. (BM 960581!). Syn. Nov.

Polytrichadelphus valenciae (Müll. Hal.) Paris, Index Bryol. 994. 1898. Catharinea valenciae Müll. Hal., Linnaea 42: 468. 1879. Tipo: Venezuela, Fendler s.n. (NY 1408289!, 1408288! y P 131386!). Syn. Nov.

Polytrichadelphus cuspidirostrum (Schimp.) Broth., Nat. Pflanzenfam. I (3): 683. 1905. Polytrichum cuspidirostrum Schimp., Nuovo Giorn. Bot. Ital., n.s. 4: 16. 1897. Tipo: Bolivia, Müller 1223 (JE4004390!). Syn. Nov.

Polytrichadelphus bolivianus Herzog, Biblioth. Bot. 87: 103. 1916. Tipo: Bolivia, Herzog 5083; (Lectotipo designado por Colotti et al., 2013.JE!). Syn. Nov.

Polytrichadelphus mitis Herzog, Hedwigia 67: 267. 1927. Tipo: Bolivia, Buchtier 1920 (JE!). Syn. Nov.
Polytrichadelphus subrubescens (Thér.) G. L. Sm., Phytologia 18: 403. 1969. Polytrichum subrubescens Thér., Rev. Bryol. Lichénol. 9: 6. F. 1. 1936. Tipo: Ecuador, Benoist 4658 (P 131221!, 131222 ! y 131223!). Syn. Nov.

Polytrichadelphus ciferrii Herzog \& Giacom., Ist. Bot. Reale Univ. Reale Lab. Crittog. Pavia, Atti 9(2): 215. A-e. 1950. Tipo: Venezuela, Ciferri 1947 (JE 4004391!). Syn. Nov.

Plantas pequeñas a grandes, de hasta $13 \mathrm{~cm}$ de longitud; pardo rojizo oscuro a pardo verdoso. Tallo simple o ramificado. Hojas de 3,5-10 x 0,5-2 $\mathrm{mm}$; deltoides; diferenciadas en vaina y limbo; limbo plano, multiestratificado, 2-7 mm de largo; margen leve a fuertemente serrado, dientes uni o pluricelulares, células isodiamétricas a rectangulares; ápice agudo, aristado o largo aristado; vaina amplectante, parcial o totalmente anaranjada; nervio fuerte, percurrente a largo excurrente, generalmente entero en el envés; lamelas sobre el nervio y parte de la lámina; en sección transversal, 38-48 filas de lamelas, 5-7 células de alto, célula lamelar apical diferenciada, piriforme, de pared delgada, lisa, de 5-10 $\mu \mathrm{m}$ de ancho. Células de la epidermis ventral de 2-10 x 5-15 $\mu \mathrm{m}$; células guía de 4-10 x 5-15 $\mu \mathrm{m}$; células de la epidermis dorsal de 2-10 x 5-15 $\mu$ m; células del limbo de 5-50 x 2-15 $\mu$ m; células de la vaina de 35-120 x 4-10 $\mu$ m; células de los hombros de 2-1 x 8-20 $\mu \mathrm{m}$.

Dioicas. Periquecio terminal o axilar; arquegonios abundantes; hojas periqueciales diferenciadas, 3-10 x 0,5-2,5 mm, ápice agudo a aristado, margen entero o dentado; paráfisis filiformes, adundantes. Perigonio terminal; anteridios abundantes, cilíndricos, 1,52,0 $\mathrm{mm}$ de largo; hojas perigoniales diferenciadas, lanceoladas a orbiculares, 8-10 x 2-3 mm, ápice agudo, margen entero o dentado; paráfisis clavadas, abundantes. Esporofito solitario. Seta lisa, roja o parda, 2-10 cm de largo, recta. Cápsula bi-angulada, inclinada u horizontal, 3-5 mm de largo; células del exotecio de 20-40 x 25-50 $\mu \mathrm{m}$. Peristoma de 64 dientes de $60-100 \times 10-25 \mu \mathrm{m}$. Caliptra cuculada, de hasta $7 \mathrm{~mm}$, parda o amarilla, glabra con espinas en el ápice.

Material estudiado. COLOMBIA. Dpto. Antioquia, Belmira, $6^{\circ} 41^{\prime} \mathrm{N} 75^{\circ} 40^{\prime} \mathrm{W}, 2445-2935 \mathrm{~m}$, 
23-IV-91, Churchill 17796 (COL-HUA-NY); Dpto. Boyacá, Sta. Rosita, 3300 m, 05-V-73, Cleef 9753 (COL-NY); Dpto.Caldas, Manizales, 2500 m, 16VII-65, Merrill King 898 (COL); Dpto. Caquetá, San Vicente del Caguán, $2^{\circ} 47^{\prime} \mathrm{N} 75^{\circ} 01^{\prime} \mathrm{W}, 2000 \mathrm{~m}$, 24-XI-90, Churchill 16822 (COL-HUA-NY); Dpto. Casanare, Sácama, 6004'42”N 7209'89”W, 1060 m, 27-I-95, Churchill 18957 (COL-NY); Dpto. Cauca, Puracé, 3150 m, 04-III-79, Luteyn 6930 (COL-HUA-NY); Dpto. Chocó, El Cármen, 2150 m, 19-VII-86, Churchill 14539 (COL-HUA-NY); Dpto. Cundinamarca, Silvania, 2700 m, 26-VIII92, Linares 3877 (COL-HUA-NY); Dpto. Huila, Campoalegre, 2170 m, 29-VIII-92, Llanos 2449 (COL); Dpto. Magdalena, Santa Marta, 2150 m, 14-I-67, Mägdefrau 1105 (COL); Dpto. Meta, Restrepo, 570 m, 28-VI-79, Pinto 23 (COL); Dpto. Nariño, Pasto, 3900 m, 14-I-91, Churchill 17477 (COL-HUA-NY); Dpto. Norte de Santander, Toledo, 7¹1'64”N 72²6'56”'W, $1180 \mathrm{~m}, 24$ I-95, Churchill 18869 (COL-HUA-NY); Dpto. Putumayo: Mocoa, 1150 m, 04-V-94, GiraldoCañas 2175(COL); Dpto. Quindio, Salento, 2950 m, 20-XI-90, Uribe 1176 (COL); Dpto. Risaralda, Santa Rosa de Cabal, 2600 m, 16-VII- 1980, Gradstein 3561 (COL); Dpto. Santander, Charalá, 1900 m, 06-III-81, Aguirre 2062 (COL); Dpto. Tolima, Ibagué, 1750 m, 06-XI-82, Esquivel 35 (COL); Dpto. Valle del Cauca, Cali, $3^{\circ} 30^{\prime} \mathrm{N}$ 76³5'W, $2000 \mathrm{~m}, 22-\mathrm{VI}-87$, Churchill 15183 (COL-CUVC-HUA-NY). COSTA RICA. Prov. San José, 2100 m, IV 1951, Schultes 11918 (COL); ECUADOR. Prov. Zamora-Chinchipe, $3^{\circ} 59^{\prime} \mathrm{S}$ 7908'W, 2400 m, 16-IV-73, Holm-Nielsen 3578 (COL).

Distribución geográfica. En Colombia se encuentra en los departamentos de Antioquia, Boyacá, Caldas, Caquetá, Casanare, Cauca, Chocó, Cundinamarca, Huila, Magdalena, Meta, Nariño, Norte de Santander, Putumayo, Quindío, Risaralda, Santander, Tolima, Valle del Cauca y Vaupés entre 90-4400 m de altitud (Fig. 14). También ha sido reportada de Venezuela, Ecuador, Perú, Bolivia, Brasil y Argentina (Churchill, 2000).

Hábitat. Se encuentra frecuentemente en barrancos, sobre suelo o sobre roca, en terrenos de arcilla o arenisca, rara vez sobre troncos. En bosques intervenidos y en páramo.
Observación. Se distingue fácilmente por tener el limbo predominantemente entero en la superficie abaxial (a veces presentan unas pocas espinas muy cerca del ápice). Se trata de una especie con amplia variación morfológica, que incluye, margen entero hasta fuertemente serrado, ápice agudo hasta largo apiculado y longitud variable de la seta.

Smith (1971) afirmó con respecto a Polytrichadelphus, que en su opinión, quizá el norte de Suramérica era un centro de especiación secundario (el original sería el sur del continente), lo que podría explicar que la mayoría de especies se encuentren en el norte de los Andes, sin embargo, consideró que se trataba de un número sobre estimado. Para Colombia, Churchill \& Linares (1995) y Churchill (2016) reportaron a Polytrichadelphus abriaquiae, P. aristatus, $P$. longisetus, $P$. rubiginosus, $P$. valenciae y $P$. trianae, diferenciándolas por la ornamentación del margen de la hoja y la forma del ápice, principalmente.

Luego de observar los ejemplares tipo de la mayoría de las especies de Polytrichadelphus de Suramérica, se evidencia que la variación de los caracteres no ofrece el soporte necesario para considerar que se trate de entidades diferentes, sino que corresponde a una sola especie Polytrichadelphus longisetus, con un amplio rango de variación morfológica.

Polytrichastrum G.L. Sm.

Polytrichastrum G.L. Sm., Mem. New York Bot. Gard. 21 (3): 35. 1971.

Tipo: Polytrichum alpinum Hedw. [= Polytrichastrum alpinum (Hedw.) G.L. Sm.]

Polytrichastrum tenellum (Müll. Hal.) G.L. Sm.

Polytrichastrum tenellum (Müll. Hal.) G.L. Sm., Bryologist 78: 201. 1975. Polytrichum tenellum Müll. Hal., Nuovo Giorn. Bot. Ital., n.s. 4: 17.1897. Tipo: Germain, Bolivia (H, FI). Fig. 15

Polytrichastrum alpiniforme (Card.) G. Sm. Mem.New York Bot. Gard. 21 (3): 35. 1971 Polytrichum alpiniforme Cardot, Rev. Bryol. 37: 6. 1910.Tipo: México, Pringle 15187 (P 131152!, 131153 !).

Plantas pequeñas a grandes de hasta $20 \mathrm{~cm}$ de longitud; pardo rojizo oscuro. Tallo simple. Hojas de 4-15 x 0,5-2 mm; deltoides; diferenciadas en 
Bol. Soc. Argent. Bot. 52 (2) 2017

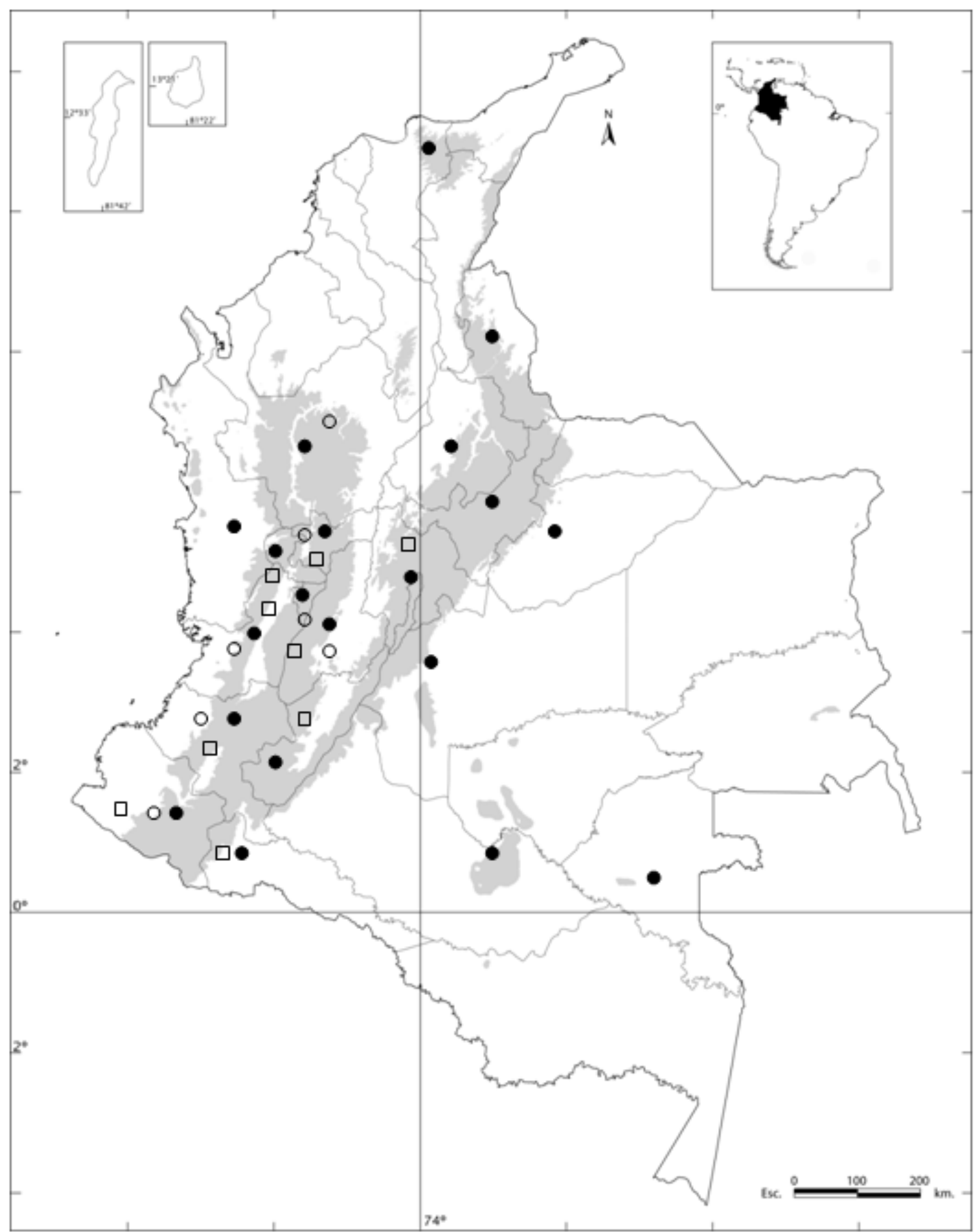

Fig. 14. Distribución geográfica departamental de Polytrichadelphus en Colombia (P. ciliatus (०), $P$. longisetus (•) y $P$. giganteus ( $\square)$ ). 
vaina y limbo; limbo multiestratificado, 2,5-12 $\mathrm{mm}$ de largo; margen involuto o erecto, fuertemente serrado, dientes grandes; ápice acuminado; vaina amplectante, amarilla; nervio fuerte, excurrente, espinoso en el envés; lamelas sobre el nervio y parte de la lámina; en sección transversal, 30-56 filas de lamelas, 6-9 células de alto, célula lamelar apical diferenciada, piriforme, papilosa, de 10-15 $\mu \mathrm{m}$ de ancho. Células de la epidermis ventral de

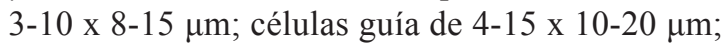
células de la epidermis dorsal de 2-5 x 5-20 $\mu \mathrm{m}$; células del limbo de 5-20 x 4-15 $\mu \mathrm{m}$; células de la vaina de 50-120 x 4-10 $\mu \mathrm{m}$; células de los hombros de 2-10 x 5-15 $\mu \mathrm{m}$.

Dioicas. Periquecio indiferenciado; arquegonios escasos; hojas periqueciales levemente diferenciadas, deltoides, 4-6 x 1-2 mm, ápice agudo, margen serrado; paráfisis no vistos. Perigonio no visto. Esporofitos no vistos.

Material estudiado. COLOMBIA. Dpto. Boyacá, Páramo de Pisva, 3500 m, 08-VI-72, Cleef 4237 (COL-NY); Dpto. Cesar, La Paz, 10¹5'3.1'N 7257'26,9”'W, 3110 m, 26-II-06, Avendaño 399 (COL); Dpto. Cundinamarca, La Calera, 3490 m, 22-VII-65, Merrill King 998 (COL); Dpto. Magdalena, Sierra Nevada de Santa Marta, 3550 m, 08-X-69, Cuatrecasas 24653 (COL). PERU. Dpto. Ancash, Prov. Huaraz, National Park, 9 ${ }^{\circ} 31^{\prime} \mathrm{S} / 7^{\circ} 25^{\prime} \mathrm{W}, 3700 \mathrm{~m}, 22-\mathrm{V}$ 85, Smith 629 (COL).VENEZUELA. Est. Mérida, Sierra de Santo Domingo, 3625 m, 28-XI-59, Barclay 9828 (COL).

Distribución geográfica. En Colombia se encuentra en los departamentos de Boyacá, Cesar,
Cundinamarca y Magdalena entre 2900-4400 m de altitud (Fig. 21). También ha sido reportada de México, Guatemala, Costa Rica, Venezuela, Ecuador, Perú y Bolivia (Smith, 1975).

Hábitat. Se encuentra en el páramo, en barranco, sobre roca o más comúnmente suelo. En sitios expuestos a la luz, cerca de quebradas.

Observación. Se distingue fácilmente porque las células apicales de las lamelas son papilosas. El espécimen sobre el cual se basó la descripción en 1897 de Polytrichastrum tenellum fue colectado en Bolivia por Germain. Smith (1975) enunció que ese ejemplar correspondía con Polytrichastrum alpiniforme, descrito en 1910, por lo que hizo el traslado nomenclatural.

Polytrichum Hedw.

Polytrichum Hedw. Sp. Musc. Frond.88: 1801.

Tipo: Polytrichum commune Hedw., Sp. Musc. Frond. 88.1801

Las principales características de las especies de Polytrichum se presentan en la Tabla 3.

\section{Clave para las especies colombianas de Polytrichum}

1. Margen del limbo involuto. P. juniperinum

1'. Margen del limbo erecto o inflexo. 2

2. Células apicales de las lamelas de varias formas en el mismo corte. P. commune

2'. Células apicales de las lamelas siempre con forma de U. P. ericoides

Tabla 3. Comparación entre algunas caracteristicas de las especies de Polytrichum presentes en Colombia.

\begin{tabular}{|c|c|c|c|c|}
\hline Especies & Forma del limbo & Forma del ápice del limbo & $\begin{array}{l}\text { Forma de las células } \\
\text { apicales de las lamelas }\end{array}$ & Altitud \\
\hline P. commune & Erecto & $\begin{array}{c}\text { Predominantemente } \\
\text { apiculado a largo aristado }\end{array}$ & $\begin{array}{l}\text { Varias en un mismo corte } \\
\text { (desde U hasta piriformes) }\end{array}$ & $500-3400$ \\
\hline$P$. ericoides & $\begin{array}{l}\text { Erecto a levemente } \\
\text { involuto }\end{array}$ & Agudo & $\mathrm{De} U$ & $2700-3800$ \\
\hline P. juniperinum & Involuto & $\begin{array}{l}\text { Agudo, apiculado a } \\
\text { largo aristado }\end{array}$ & Piriformes & $100-4700$ \\
\hline
\end{tabular}


Polytrichum commune Hedw.

Polytrichum commune Hedw., Sp. Musc. Frond. 88. 1801. (Tipo: Vulgaris per totam Europam.: Hedwig, J. \#106. Collection date: None; Country Unkown; Herbarium PH; Verified by Britton, E.G, 1900/04). Fig. 16

Plantas medianas a grandes de hasta $20 \mathrm{~cm}$ de longitud; verde amarillento o pardo rojizo oscuro. Tallo simple o ramificado. Hojas de 5.0-20 x 0,5$2 \mathrm{~mm}$; deltoides; diferenciadas en vaina y limbo; limbo de 3.0-12 $\mathrm{mm}$ de largo; margen erecto, fuertemente serrado; ápice agudo a largo aristado; vaina amplectante, amarilla; nervio fuerte, largo excurrente, fuertemente espinoso en el envés; lamelas sobre el nervio y parte de la lámina; en sección transversal, 20-45 filas de lamelas de 4-9 células de alto, célula lamelar apical diferenciada, con forma de U hasta piriforme, lisa, de 8.0-20 $\mu \mathrm{m}$ de ancho. Células de la epidermis ventral de 4-10 x 6-20 $\mu \mathrm{m}$; células guía de 6-15 x 5-25 $\mu \mathrm{m}$; células de la epidermis dorsal de 2-10 x 5-15 $\mu \mathrm{m}$; células del limbo de 5-20 x 4-20 $\mu$ m; células de la vaina de 50-160 x 4-15 $\mu \mathrm{m}$; células de los hombros de 1-10 $\mathrm{x} 10-25 \mu \mathrm{m}$.

Perigonio no visto. Periquecio no visto. Esporofito no visto.

Material estudiado. COLOMBIA. Dpto. Caquetá, San Vicente del Caguán, $2^{\circ} 30^{\prime} \mathrm{N}$ 74²4'W, $500 \mathrm{~m}, 02-X I I-90$, Churchill 17033 (COL-HUA); Dpto. Cundinamarca, Páramo de Chingaza, 3300 m, 03-I-69, Cuatrecasas 26977 (COL); Dpto. Norte de Santander, Pamplona, 7.891N 72.6713 W, 2674 m, 25-XII-09, Benavides 5299 (COL); Dpto. Santander, Páramo del Almorzadero, 3450 m, 26-VII-85, Escobar 343 (HUA).

Distribución geográfica. Cosmopolita. En Colombia se encuentra en los departamentos de Caquetá, Norte de Santander y Santander entre $500-3500 \mathrm{~m}$ de altitud (Fig. 21).

Hábitat. Sobre suelo arenoso, en suelo con hojarasca y en una laguna de turbera.

Observación. Polytrichum commune se distingue por las hojas fuertemente serradas y por las células terminales de las lamelas, que várían desde piriformes en los extremos hasta en forma de U en la zona central de un mismo corte transversal.

\section{Polytrichum ericoides Hampe}

Polytrichum ericoides Hampe, Ann. Sci. Nat., Bot., sér.5, 4: 350.1865 Tipo: Colombia, Lindig s.n. (BM 960749!). Fig. 17

Plantas medianas a grandes de hasta $12 \mathrm{~cm}$ de longitud; verde, pardo, o pardo rojizo oscuro. Tallo simple o ramificado. Hojas de 3.5-6.0 x 0.5-1.0 mm en la zona media y $0,5-1,5 \mathrm{~mm}$ de ancho en la base; deltoides; diferenciadas en vaina y limbo; limbo plano,de 1,5-3,5 mm de largo; margen involuto o erecto, fuertemente serrado; ápice agudo; vaina amplectante, amarilla; nervio fuerte, percurrente, espinoso en el envés; lamelas sobre el nervio y parte de la lámina; en sección transversal, 28-50 filas de lamelas de 6-11 células de alto, célula lamelar apical diferenciada, en forma de U, lisa, de 7.0-20 $\mu \mathrm{m}$ de ancho. Células de la epidermis ventral de 5-15 x 4-15 $\mu \mathrm{m}$; células guía de 3,5-10 x 8-15 $\mu \mathrm{m}$; células de la epidermis dorsal de 2-5 x 6-15 $\mu \mathrm{m}$; células del limbo de 4.0-15 x 5.0-15 $\mu \mathrm{m}$; células de la vaina de $65-120 \times 5-10 \mu \mathrm{m}$; células de los hombros de 2.0-6.0 x 10-15 $\mu \mathrm{m}$.

Dioicas. Periquecio terminal; arquegonios escasos; hojas periqueciales diferenciadas, deltoides a acintadas, 4-7 x 0,5-1,5 mm, ápice agudo, margen serrado; paráfisis filiformes, escasas. Perigonio terminal; anteridios abundantes, cilíndricos, 1-2 $\mu \mathrm{m}$ de largo; hojas perigoniales diferenciadas, lanceoladas a orbiculares, 1,5- 4 x 1-2,5 mm, ápice agudo, margen y envés levemente serrado; paráfisis clavadas, hialinas a verdes, abundantes. Esporofito no visto.

Material estudiado. COLOMBIA. Dpto. Antioquia, Urrao, $6^{\circ} 25^{\prime} \mathrm{N} 76^{\circ} 05^{\prime} \mathrm{W}, 3500 \mathrm{~m}, 30$-VI85, Churchill 13325 (COL-HUA-NY); Dpto. Boyacá, Páramo de Pisva, 3590 m, 11-VI-72, Cleef 4422 (COL-NY); Dpto. Cundinamarca, Bogotá, 3230 m, 18-IV-69, Sturm 9 (COL); Dpto. Meta, Páramo de Sumapaz, 3650 m, 22-I-73, Cleef 8245 (COL).

Distribución geográfica. En Colombia se encuentra en los departamentos de Antioquia, Boyacá, Cundinamarca y Meta entre 2700 y 3800 $\mathrm{m}$ de altitud (Fig. 21). También ha sido reportada de Venezuela, Ecuador y Bolivia (Churchill et al., 2000) 
A. Aponte-R. y J. Uribe-M. - Revisión de la familia Polytrichaceae para Colombia

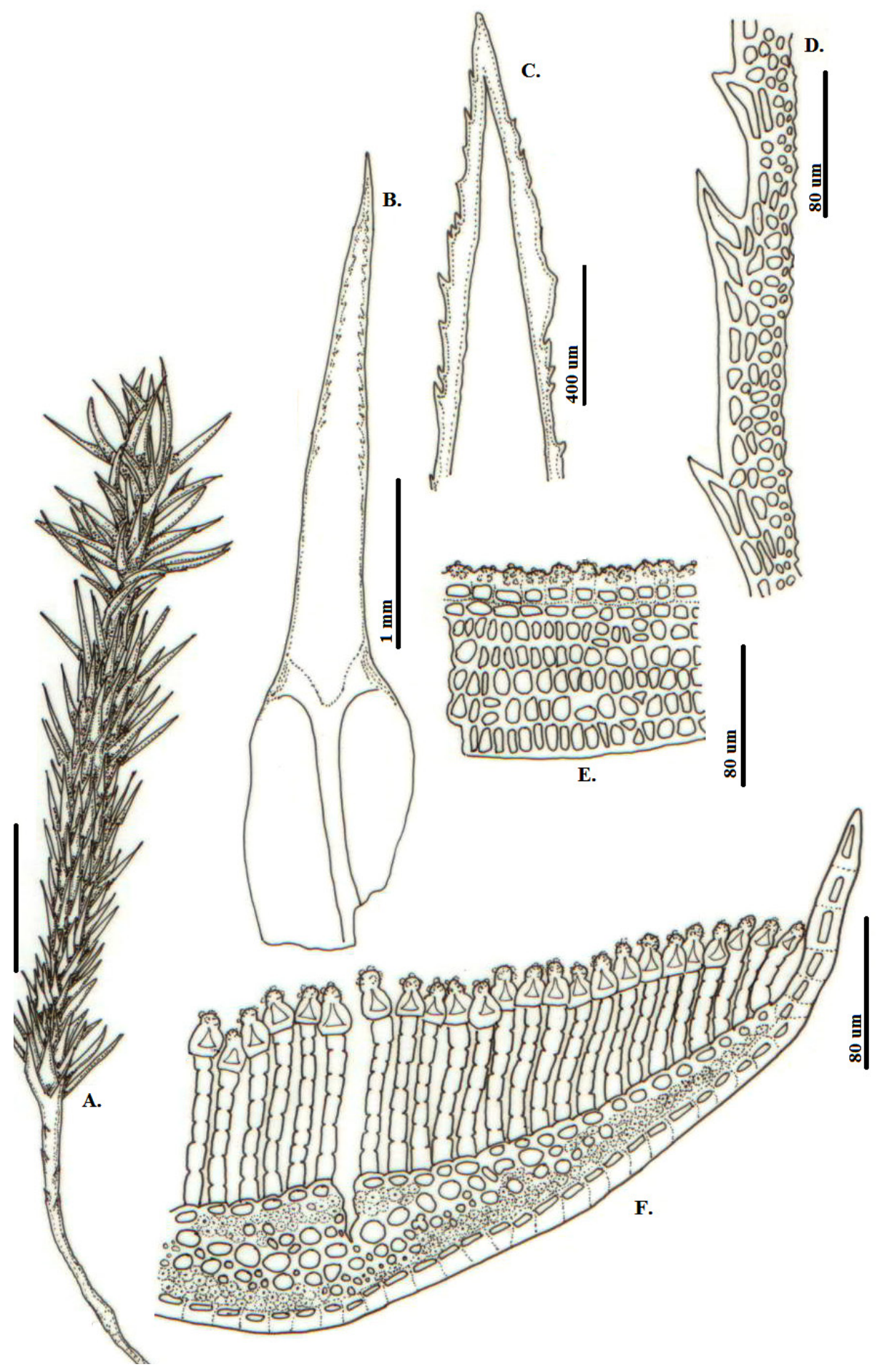

Fig. 15. Polytrichastrum tenellum (Müll. Hal.) G.L. Sm.: A. Hábito, B-F. Hoja, B. Vista general, C. Detalle del ápice, D. Detalle del margen, E. Vista lateral de las lamelas, F. Corte transversal [B. de Uribe 871, A, C-F, de Florchütz 4054]. 
Bol. Soc. Argent. Bot. 52 (2) 2017

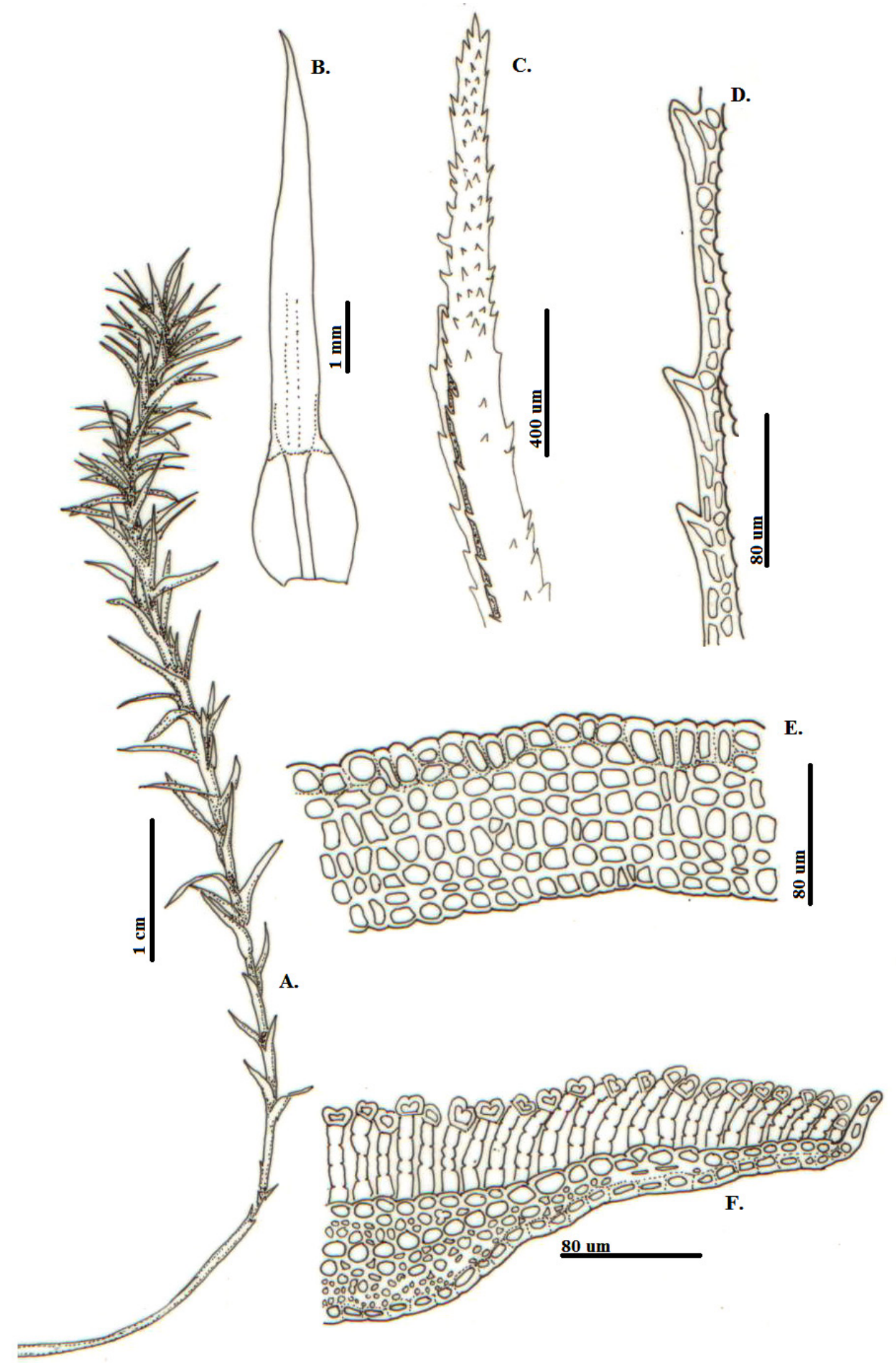

Fig. 16. Polytrichum commune Hedw.: A. Hábito, B-F. Hoja, B. Vista general, C. Detalle del ápice en vista abaxial, D. Detalle del margen, E. Vista lateral de las lamelas, F. Corte transversal [Todas de Benavides 5299]. 
A. Aponte-R. y J. Uribe-M. - Revisión de la familia Polytrichaceae para Colombia

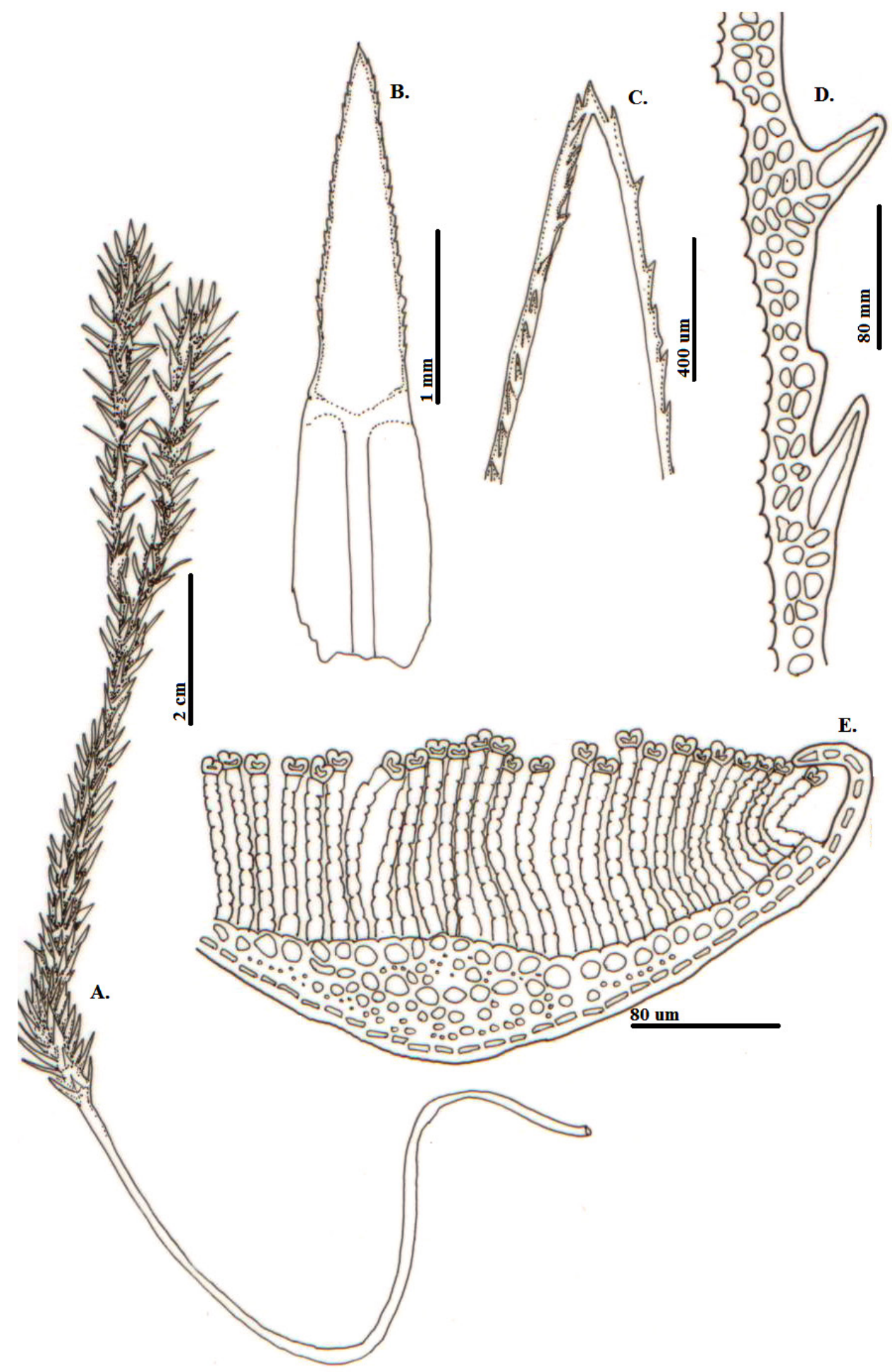

Fig. 17. Polytrichum ericoides Hampe: A. Hábito, B-E. Hoja, B. Vista general, C. Detalle del ápice, D. Detalle del margen, E. Corte transversal [Todas de Cleef 9513]. 
Hábitat. Polytrichum ericoides es una especie bastante común en el páramo, generalmente asociada a turberas.

Observación. Se distingue fácilmente por las células apicales de las lamelas con forma de U y por las hojas erecto-patentes o imbricadas. Polytrichum ericoides es muy similar a $P$. commune se diferencian en el tamaño del limbo con relación a la vaina, la forma del ápice y la ubicación de las hojas con respecto al tallo. En estudios realizados por Bell \& Hyvönen (2010a, 2010b) formaron parte de un mismo clado, pero al ser distinguibles morfológicamente, hasta tanto no se haga un estudio molecular con poblaciones neotropicales, se seguirán considerando entidades diferentes.

\section{Polytrichum juniperinum Hedw.}

Polytrichum juniperinum Hedw. Sp. Musc. Frond. 89. pl. 18: f. 6-10. 1801. Tipo: "Suiza. Locus montanus subalpestris, delineata exemplo ex Helvetia, s. col. Hedwig, J. \#28." Fecha de colección: No registrada; País: Desconocido; Herbario PH; Verificado por Britton, E.G, 1900/04". Fig. 18

Plantas pequeñas a grandes, de hasta $12 \mathrm{~cm}$ de longitud; verde amarillento, pardo o pardo rojizo oscuro; Tallo simple o ramificado. Hojas de 4,2$12 \times 0,5-1,5 \mathrm{~mm}$; deltoides; diferenciadas en vaina y limbo; limbo multiestratificado, 2,5-10 mm de largo; margen involucro sobre el limbo, entero; ápice agudo, acuminado o largo acuminado; vaina amplectante, amarilla; nervio fuerte, percurrente o largo excurrente, entero a fuertemente espinoso en el envés; lamelas sobre el nervio y parte de la lámina, en sección transversal 20-45 filas de lamelas de 5-8 células de alto, célula lamelar apical diferenciada, piriforme, simple, lisa, de 10-20 $\mu \mathrm{m}$ de ancho. Células de la epidermis de 5-15 x 5-20 $\mu \mathrm{m}$; células guía de 5-15 x 5-20 $\mu \mathrm{m}$; células de la epidermis dorsal de 2-10 x 5-15 $\mu \mathrm{m}$; células del limbo de 4-20 x 30-60 $\mu \mathrm{m}$; células de la vaina de 60-170 x 5-20 $\mu$ m; células de los hombros de 2,5$12,5 \times 10-30 \mu \mathrm{m}$.

Dioicas. Periquecio terminal o axilar; arquegonios urceolados; hojas periqueciales diferenciadas, deltoides a acintadas, de 2,5-6 x 1-2 mm, ápice largo aristado, espinoso; paráfisis filiformes, abundantes. Perigonio terminal; anteridios abundantes, cilíndricos de 1-2 mm de largo; hojas perigoniales diferenciadas, lanceoladas a orbiculares, de 7,5-10 x 1-2 mm, ápice agudo; paráfisis clavadas, verdes, abundantes. Esporofito solitario. Seta lisa, roja, 4-7 cm de largo, recta. Cápsula cilíndrica, erecta u horizontal, 4-angulada, 3-5 mm de largo, con apófisis; estomas en la base; células del exotecio de 15-20 x 14-20 $\mu \mathrm{m}$. Peristoma de 64 dientes, de 200-220 x 45-65 $\mu \mathrm{m}$. Caliptra de hasta $8 \mathrm{~mm}$ de largo, parda, amarilla o dorada, pilosa.

Material estudiado. COLOMBIA. Dpto. Antioquia, Medellín, 6¹0’N 75³0'W, 2000 m, 14VI- 85, Sastre 891 (COL-HUA-NY); Dpto. Arauca, Sierra Nevada del Cocuy, 4285 m, 07-III-73, Cleef 8840 (COL); Dpto. Boyacá, Sierra Nevada del Cocuy, 3970 m, 04-III-73, Cleef 8779 (COL-NY); Dpto. Caldas, Nevado del Ruíz, 4680 m, 18-III72, Cleef 2404 (COL-NY); Dpto .Caquetá, San Vicente del Caguán, 2000 m, 24-XI-90, Churchill 16824 (COL-HUA); Dpto. Casanare, La Salina, 2700 m, 18-VIII-82, Aguirre 3219 (COL); Dpto. Cauca, Coconuco, $2^{\circ} 24^{\prime} \mathrm{N} 76^{\circ} 24^{\prime} \mathrm{W}, 3000 \mathrm{~m}, 11$ I-91, Churchill 17260 (COL-HUA); Dpto. Chocó, Quibdó, 90 m, 19-XI-04, Pino 60 (COL); Dpto. Córdoba, San Andrés, 1500 m, 21-V-61, Romero C. 8984 (COL); Dpto. Cundinamarca, Cogua, 3470 m, 24-XI-71, Cleef 68 (COL-NY); Dpto. Huila, Parque Puracé, 3420 m, 05-II-84, Barbosa 2448 (COL); Dpto. Magdalena, Sierra Nevada de Santa Marta, $10^{\circ} 59^{\prime} \mathrm{N} 74^{\circ} 01^{\prime} \mathrm{W}, 1800 \mathrm{~m}, 06-\mathrm{IX}-72$, Kirkbride 2099 (COL-NY); Dpto. Meta, Páramo de Sumapaz, 3460 m, 21-I-72, Cleef 817 (COL); Dpto. Nariño, Pasto. $1^{\circ} 12^{\prime} \mathrm{N} 77^{\circ} 20^{\prime} \mathrm{W}, 3000 \mathrm{~m}$, 6-XI-1988, Churchill 15971 (COL-HUA-PSO); Dpto. Norte de Santander, Pamplona, $7^{\circ} 18^{\prime} 05^{\prime} \mathrm{N}$ 72³6’09”'W, 2260 m, 24-I-95, Churchill 18839 (COL-NY); Dpto. Putumayo, El Encano, 3250 m, 04-I-41, Cuatrecasas 11747 (COL); Dpto. Quindio, 2200 m, VII 1855, Triana 560 (COL); Dpto. Risaralda, Pereira, 2550 m, 17-VI- 1989, Uribe 332 (COL); Dpto. Santander, California, $7^{\circ} 19^{\prime} \mathrm{N}$ 7256'W, 2200 m, 23-I-95, Churchill 18802 (COLNY); Dpto. Tolima, Murillo, 456’N 75¹6-19’W, 3975 m, 09-V-91, Churchill 17891 (COL-HUA); Dpto. Valle del Cauca, Dagua, $3^{\circ} 30^{\prime} \mathrm{N} 76^{\circ} 40^{\prime} \mathrm{W}$, 1340 m, 24-VI-87, Churchill 15221 (COL-CUVCHUA); NUEVA GRANADA: Plantae Expeditionis Botanicae Mutisii Vice-regni Novae-Granatae, 
A. Aponte-R. y J. Uribe-M. - Revisión de la familia Polytrichaceae para Colombia
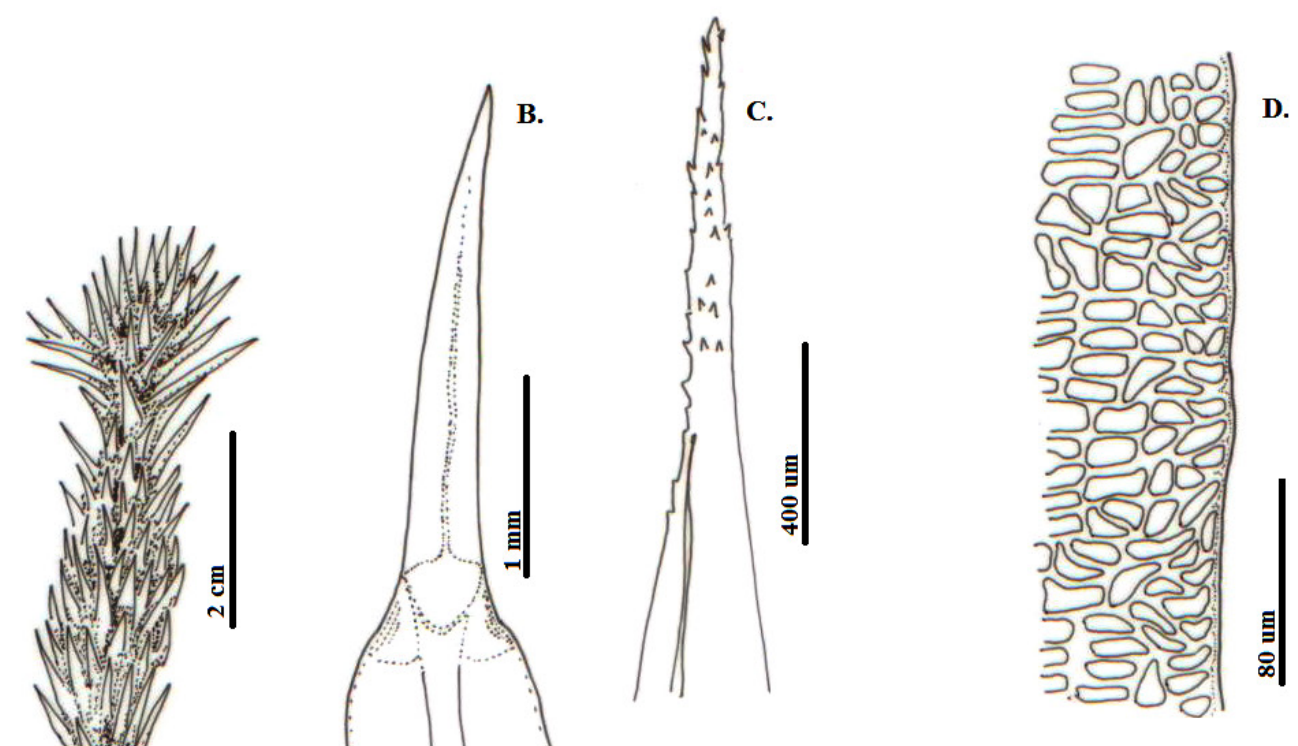

A.

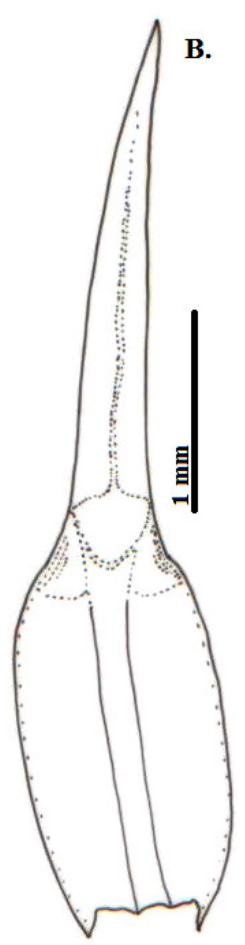

E.
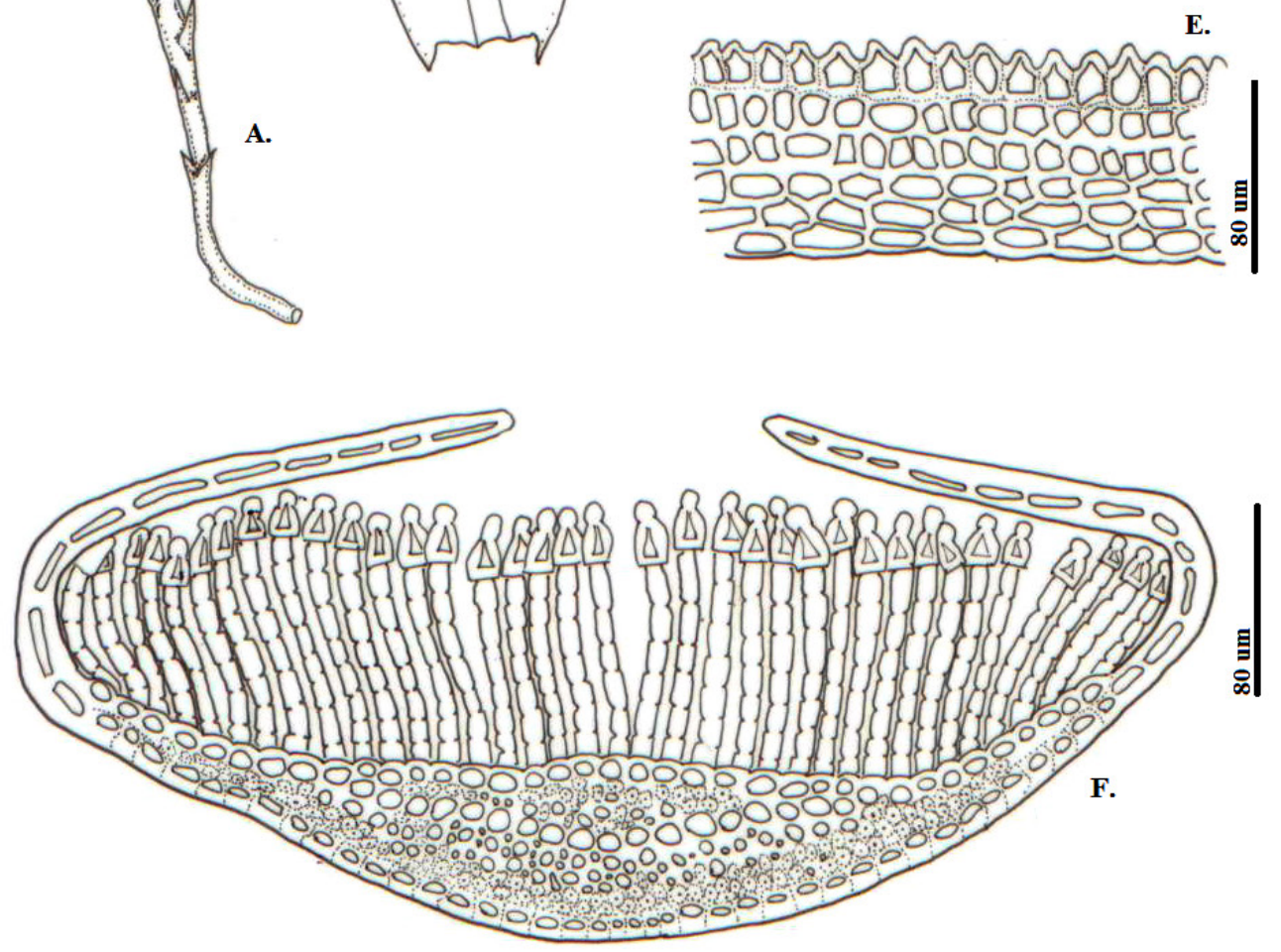

Fig. 18. Polytrichum juniperinum Hedw., A. Hábito, B-F. Hoja, B. Vista general, C. Detalle del ápice, D. Detalle del margen, E. Vista lateral de las lamelas, F. Corte transversal [A-B, de Cleef 8840a, C-D, de Aguirre 342, E. de Churchill 15644, F. de Soejarto 3704]. 
1783-1808, Mutis 3388 (COL). BOLIVIA. Dpto. Santa Cruz, Bellavista, 1749'10"'S 6440'30”'W, 2600 m, 13-IV-03, Vargas 6878 (COL); Dpto. Tarija, Prov. Arce, Padacaya, $21^{\circ} 58^{\prime} 45^{\prime} \mathrm{S}$ 643' 50 ”'W, 2490 m, 09-XI-04, Churchill 23515 (COL); CHILE. 240 m, I-24, Hollermayer 56 (COL); COSTA RICA. Prov. San José, IV1951, Schultes 11925 (COL); ECUADOR. Prov. Chimborazo, Zamora, 4300 m, 11-VIII-59, Barclay 8766 (COL); Prov. Cotopaxi, $0^{\circ} 57^{\prime} \mathrm{N}$ 79²'W, 2400 m, 30-VI-68, Holm-Nielsen 1090 (COL); Prov. Imbadura, $0^{\circ} 22^{\prime} \mathrm{N} 78^{\circ} 27^{\prime} \mathrm{W}, 2700$ m, 07-V-80, Holm-Nielsen 23305(COL); PERÚ. Dpto. Ancash, Prov. Huaraz, National Park, $9^{\circ} 31^{\prime} \mathrm{S} 77^{\circ} 25^{\prime} \mathrm{W}, 3700 \mathrm{~m}, 22-\mathrm{V}-85$, Smith 629 (COL). USA. Est. Michigan, Dickinson, 24-VII78, Nee 16406 (COL); Est. Oklahoma, Yukon, $61^{\circ} 00^{\prime} \mathrm{N}, 128^{\circ} 27^{\prime} \mathrm{W}, 930 \mathrm{~m}, 21-\mathrm{VIII}-78$, Vitt 23756 (COL).

Distribución geográfica. Cosmopolita. En Colombia se encuentra en los departamentos de Antioquia, Arauca (Sierra Nevada del Cocuy), Boyacá, Caldas, Caquetá, Casanare, Cauca, Cesar, Chocó, Córdoba, Cundinamarca, Huila, Magdalena, Meta, Nariño, Norte de Santander, Putumayo, Quindío, Risaralda, Santander, Tolima y Valle del Cauca es una especie muy común, entre 100-4700 m de altitud (Fig. 21).

Hábitat. Es frecuente en barrancos, sobre el suelo, rocas y troncos.

Observaciones. Cuando Messmer \& Frye (1947) examinaron lo que denominaron "grupo Polytrichum juniperinum" entre Suramérica y los Estados Unidos, resaltaron que se hacía referencia a una especie con amplia variación morfológica por lo que eran muchos los nombres que coincidían en las características que la definen, tales como el margen involuto, entero, de células alargadas transversalmente y con paredes muy engrosadas.

\section{Steereobryon G.L. Sm.}

Steereobryon G.L. Sm., Mem. New York. Bot. Gard. 21: 56. 1971. Tipo: Steereobryon subulirostrum (Schimp. ex Besch.) G.L. Sm., Mem. New York Bot. Gard. 21(3): 56. 1971.

\section{Clave para las especies \\ colombianas de Steereobryon}

1. Hojas con lamelas en filas continuas o discontinuas. S. subulirostrum

1 '. Hojas sin lamelas. S. elamellosum

Steereobryon elamellosum (Herzog) M. Menzel.

Steereobryon elamellosum (Herzog) M. Menzel, Beih. Nova Hedwigia 88: 57. 1987. Atrichum elamellosum (Herzog) Frye \& Duck., Bryologist 50: 80. 1-6. 1947. Catharinea elamellosa Herzog, Biblioth. Bot. 87: 102,f, 38:a-g. 1916 Tipo: Bolivia, Herzog 5088 (JE! P!). Fig. 19

Plantas pequeñas de hasta $1,5 \mathrm{~cm}$ de longitud; verde amarillentas. Tallo simple. Hojas de 2,5-3 x 0,5-1 mm; ovadas u oblongas; lámina plana, margen plano, diferenciado (limbado), dentado, con dientes formados por células diferenciadas, más anchas que las demás, papilosas; ápice agudo o mucronado; base de la hoja levemente amplectante, amarilla o verde amarillenta; nervio subpercurrente, con algunos dientes en el envés; sin lamelas. Células de la epidermis ventral de 10-15 x 10-15 $\mu \mathrm{m}$; células guía de 10-15 x 10-15 $\mu \mathrm{m}$; células de la epidermis dorsal de 10-15 x 5-10 $\mu \mathrm{m}$; células del limbo de 14-22 x 20-32 $\mu \mathrm{m}$; células de la base de la hoja de 30-50 x 15-20 $\mu \mathrm{m}$.

Perigonio no visto. Periquecio no visto. Esporofito no visto.

Material estudiado. COLOMBIA. Dpto. Boyacá, Tunja, 2800 m, 15-V-96, Aguirre 11708 (COL)

Distribución geográfica. En Colombia se encuentra en el departamento de Boyacá a los 2800 $\mathrm{m}$ de altitud (Fig. 21). También ha sido reportada de Bolivia (ejemplar Tipo)

Hábitat. Se encuentra asociada a barrancos, en sitios sombreados.

Observación. Se distingue por la ausencia de lamelas y porque la hoja es limbada, es decir, las células del margen son diferentes (alargadas) a las internas (cuadradas). Aunque algunos autores consideran que Steereobryon elamellosum y $S$. subulirostrum son una misma entidad (Smith, 1994; 
A. Aponte-R. y J. Uribe-M. - Revisión de la familia Polytrichaceae para Colombia

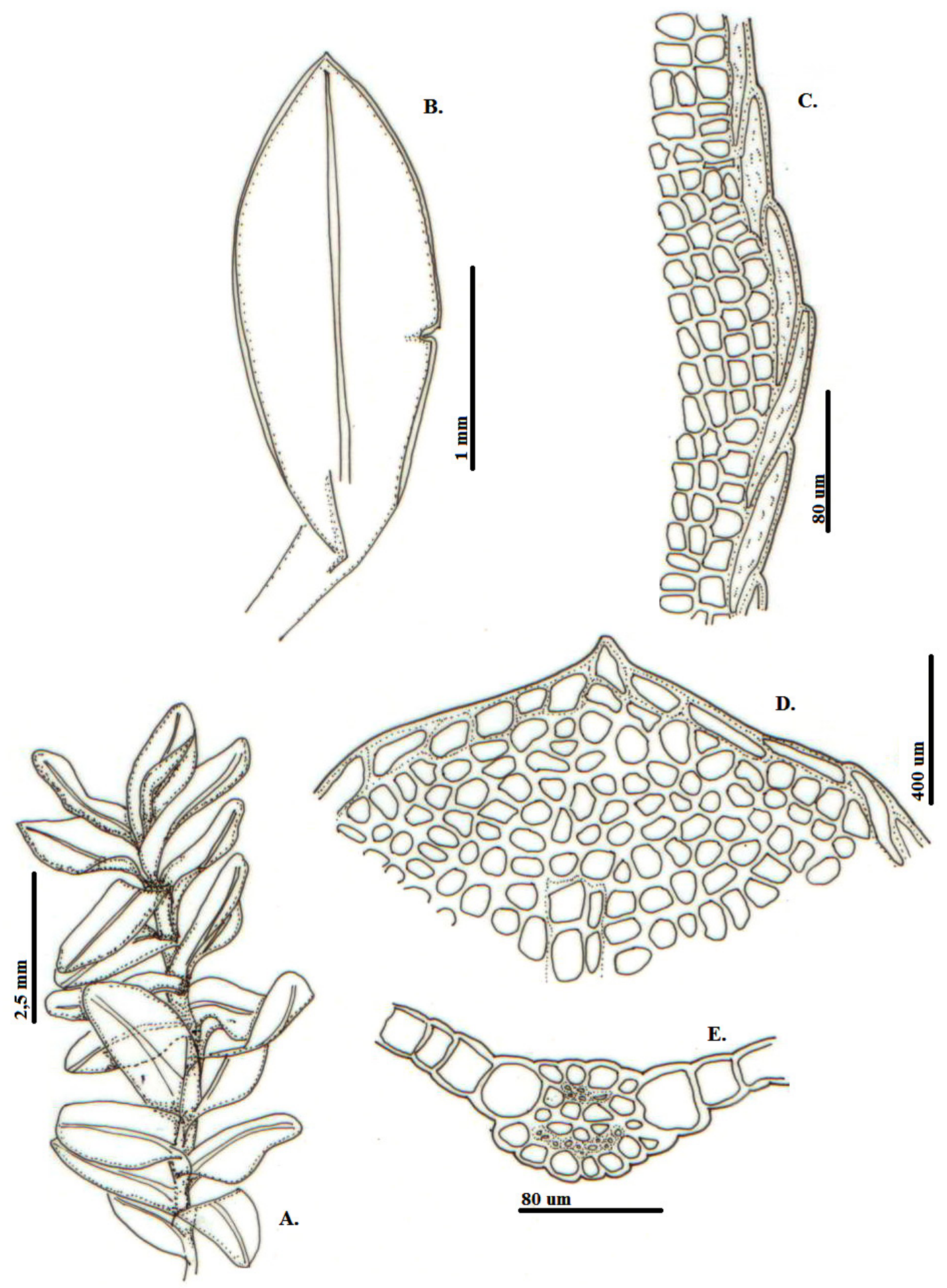

Fig. 19. Steereobryon elamellosum Hedw.: A. Hábito, B-E. Hoja, B. Vista general, C. Detalle del margen de una hoja joven, D. Detalle del ápice, E. Corte transversal [Todas de Aguirre 11708]. 
Hyvönen et al., 1998), la diferencia en la forma de las células que componen el margen y la ausencia de lamelas son caracteres suficientes para reconocer que se trata de dos especies diferenciadas. Este sería el segundo reporte de la especie, además del ejemplar Tipo colectado en Bolivia.

\section{Steereobryon subulirostrum (Schimp. ex Besch.) G.L. Sm. \\ Steereobryon subulirostrum (Schimp. ex Besch.) G.L. Sm., Mem. New York Bot. Gard. 21(3): 56. 1971. Atrichum subulirostrum Schimp. ex Besch., Mém. Soc. Sci. Nat. Math. Cherbourg 16: 205. 1872. Tipo: México. Müller s.n. (BM 960461). Fig. 20}

Plantas pequeñas de hasta $2 \mathrm{~cm}$ de longitud; verde amarillentas. Tallo simple. Hojas de 1,53 x 0,3-1,5 mm; ovadas, a oblongas; lámina plana, uniestratificada; margen plano, diferenciado (limbado), levemente dentado, dientes formados por células papilosas diferenciadas, más anchas que las demás; ápice agudo o mucronado; base de la hoja levemente amplectante; amarilla a verde amarillento; nervio subpercurrente, con algunos dientes en el envés; lamelas sobre el nervio; en sección transversal, 2-4 filas de lamelas, discontinuas y espaciadas, de 3-5 células de alto, célula lamelar apical indiferenciada, simple, lisa, 10-14 $\mu \mathrm{m}$ de ancho. Células de la epidermis ventral de 4-20 x 10-20 $\mu$ m; células guía de 5-10 x 5-15 $\mu \mathrm{m}$; células de la epidermis dorsal de 5-15 x 5-15 $\mu \mathrm{m}$; células del limbo de 10-30 x 10-30 $\mu \mathrm{m}$; células de la base de la hoja de 35-65 x 10-30 $\mu \mathrm{m}$.

Dioicas. Periquecio terminal; arquegonios escasos; hojas periqueciales poco diferenciadas, 4-6 x 1-2 mm, ápice agudo, margen dentado. Perigonio no visto. Esporofito solitario. Seta lisa, roja, 2-2,5 cm de largo, recta. Cápsula cilíndrica, erecta, 3-3,5 mm de largo; células del exotecio de 60-120 x 20-40 $\mu \mathrm{m}$, estomas en la base de la cápsula. Peristoma de 32 dientes, de 60-70 x 10$20 \mu \mathrm{m}$. Caliptra no vista, sin embargo, Churchill \& Linares (1995, pg. 651) la reportan como "lisa y desnuda".

Material estudiado. COLOMBIA. Dpto.

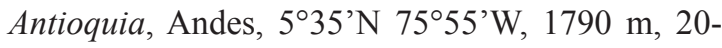
VII-86, Churchill 14546 (HUA); Dpto. Caldas, Nevado del Ruíz, 2700 m, 16 VII 1965, Merrill
King 860 (COL); Dpto. Quindio, Armenia, $4^{\circ} 28^{\prime} \mathrm{N}$ 75³3'W, 3140 m, 10-I-91, Churchill 17223 (COLHUA).

Distribución geográfica. En Colombia se encuentra en los departamentos de Antioquia, Caldas y Quindío entre los 1800 y $3150 \mathrm{~m}$ de altitud (Fig. 21). También ha sido reportada de México, Jamaica, República Dominicana, Puerto Rico (Smith, 1971; Buck \& Steere, 1983; Sastre-de Jesús \& Buck, 1993), Costa Rica (De Luna et al., 2002), Venezuela, Ecuador y Perú (Churchill et al., 2000)

Hábitat. Se encuentra en barrancos, terrenos arenosos y rocas.

Observación. Steereobryon subulirostrum estuvo incluido en el género Atrichum hasta cuando Smith (1971) lo diferenció por la presencia de estomas en la cápsula y por el margen con células papilosas. Se ha incluído en diferentes análisis moleculares, en donde generalmente resulta en un mismo clado junto con Atrichum (Forrest, 1995, en Hyvönen et al., 1998; Hyvönen et al., 2004). Adicionalmente, se notó una variación en la cantidad de filas de lamelas y de células que las conforman, ya que al observar el ejemplar tipo se evidencian en promedio 4 filas de lamelas de 8 células de alto, mientras que los ejemplares colombianos tienen hasta 5 células de alto y filas discontinuas, las descripciones para especímenes de otros países (Frye, 1948; Smith, 1994) coinciden con lo observado en los ejemplares de Colombia.

\section{Agradecimientos}

A los curadores de los herbarios BM, CAUP, COAH, COL, CUVC, HUA, JE, NY, P y PSO por el préstamo de los ejemplares de Polytrichaceae. A Fernando Sarmiento, director del Museo de la Salle y María Celeste Montilla, de la Universidad Distrital por la colaboración prestada. A la Dra. Maria Magdalena Schiavone por sus enseñanzas y comentarios a la revisión de la familia Polytrichaceae de Colombia. Por sus aportes y ejemplo a la briología latinoamericana. Al Dr. Guillermo Suárez por la invitación a participar en el homenaje a la Dra. Schiavone y por su paciencia, nuestras felicitaciones por esta gran iniciativa. 
A. Aponte-R. y J. Uribe-M. - Revisión de la familia Polytrichaceae para Colombia

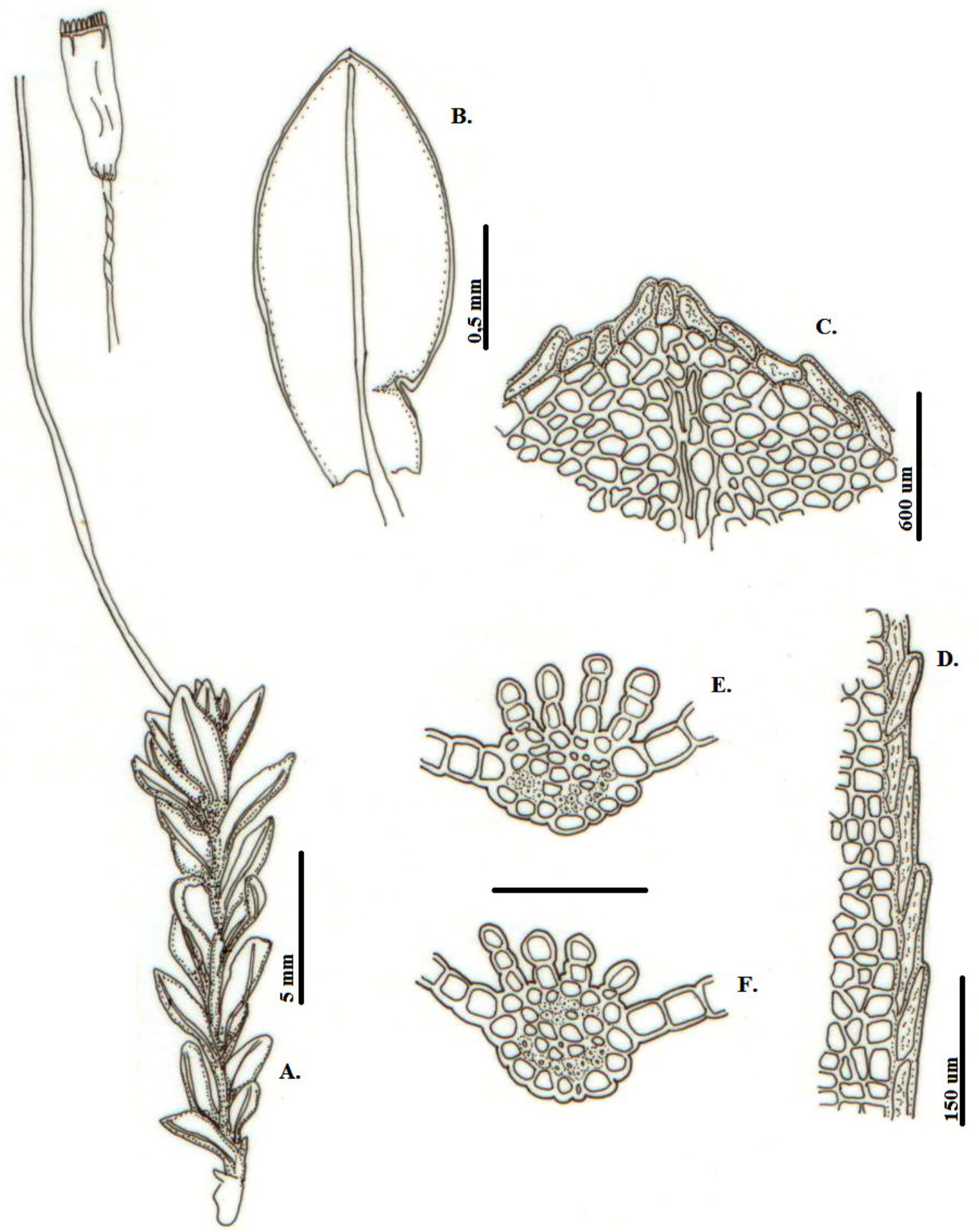

Fig. 20. Steereobryon subulirostrum (Schimp. ex Besch.) G.L. Sm.: A. Hábito, B-F. Hoja, B. Vista general, C. Detalle del ápice, D. Detalle del margen, E. y F. Corte transversal (E. en la zona media de la hoja, F. cerca al ápice) [Todas de Merril King c860]. 
Bol. Soc. Argent. Bot. 52 (2) 2017

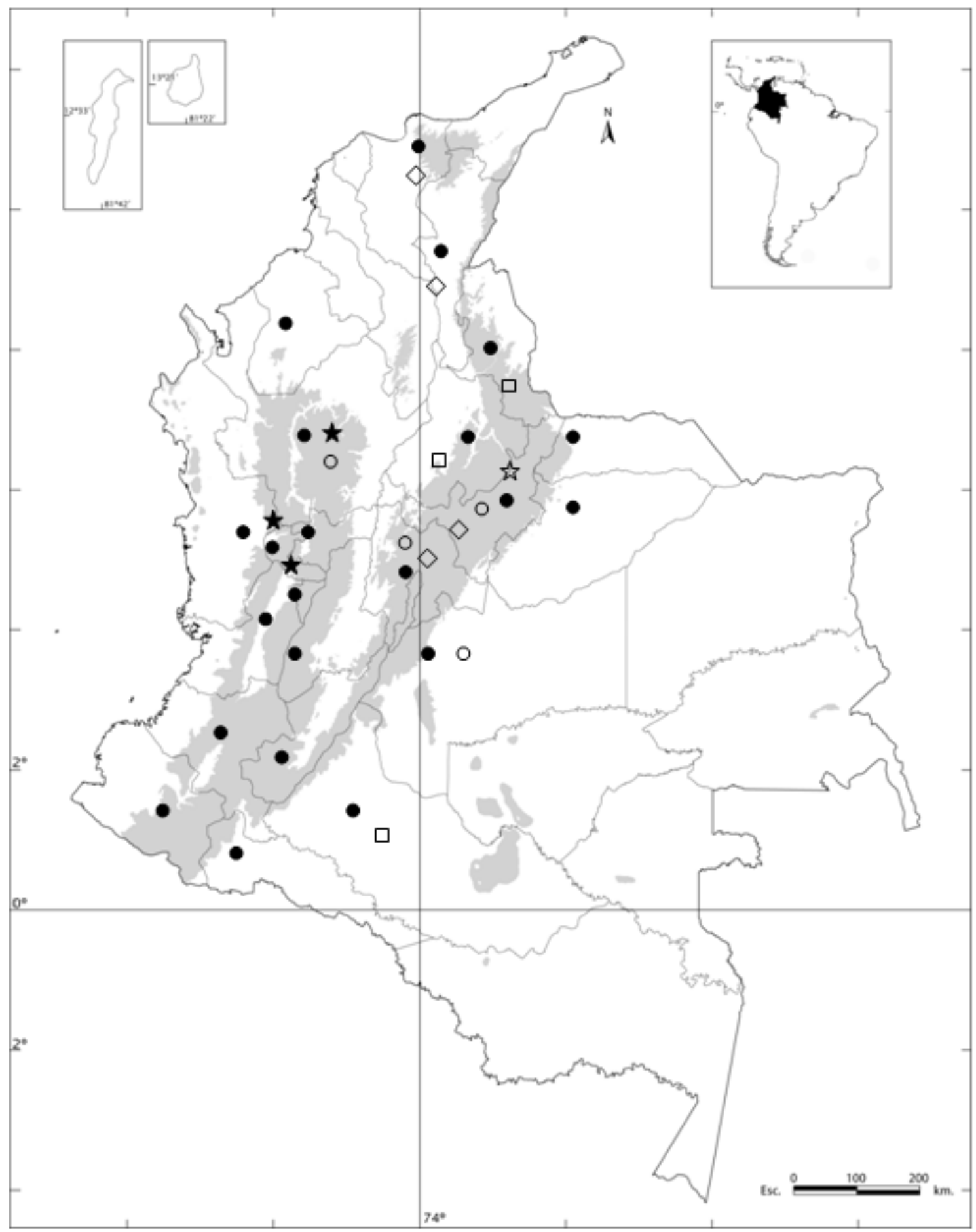

Fig. 21. Distribución geográfica departamental de Polytrichastrum tenellum ( $)$, Polytrichum commune ( $\square$ ), $P$. ericoides (०), P. juniperinum (•), Steereobryon elamellosum (estrella blanca) y $S$. subulirostrum (estrella negra) en Colombia. 


\section{A. Aponte-R. y J. Uribe-M. - Revisión de la familia Polytrichaceae para Colombia}

\section{Biblografía}

BELL, N. \& J. HYVÖNEN. 2010a. Phylogeny of the moss class Polytrichopsida (Bryophyta): Genericlevel structure and incongruent gene trees. Molec. Phylogen. Evol.55: 381-398

BELL, N. \& J. HYVÖNEN. 2010b. A phylogenetic circumscription of Polytrichastrum (Polytrichaceae): reassessment of sporophyte morphology supports molecular phylogeny. Amer. J. Bot. 97(4): 566-578.

BUCK, W. R. \& W. C. STEERE. 1983. Un listado preliminar de los musgos de La Española. Moscosoa 2: 28-53.

CHURCHILL, S. P. 2009. Moss Diversity and Endemism of the Tropical Andes. Ann. Missouri Bot. Gard. (96) 3: 434-449.

CHURCHILL, S. P. 2016. POLYTRICHACEAE. En Bernal, R., S.R. Gradstein \& M. Celis (Eds.). 2016. Catálogo de Plantas y líquenes de Colombia. Instituto de Ciencias Naturales, Universidad Nacional de Colombia, Bogotá.

CHURCHILL, S. P. \& E. L. LINARES C. 1995. Prodromus Bryologiae Novo Granatensis. Bibliot. José Jerónimo Triana 12: 1-924.

CHURCHILL, S. P., D. GRIFFIN III \& J. MUÑOZ. 2000. A checklist of the mosses of the tropical Andean countries. Ruizia. Tomo 17, Monografias del Real Jardín Botánico. Madrid

CHURCHILL, S. P., N. SANJINES \& C. ALDANA. 2009. Catálogo de las briofitas de Bolivia: diversidad, Distribución geográfica y ecología. Missouri Botanical Garden \& Museo Noel Kempff Mercado.

COSTA, D. P., K.C. PÔRTO, A. P. LUIZI-PONZO, A. L. ILKIU-BORGES, C. J. P. BASTOS, P. E. A. S. CÂMARA, D. F. PERALTA, S. B. V. BÔAS-BASTOS, C. A. A. IMBASSAHY, D. K. HENRIQUES, H. C. S. GOMES, L. M. ROCHA, N. D. SANTOS, T. S. SIVIERO, T. F. VAZIMBASSAHY \& S. P. CHURCHILL. 2011. Synopsis of the Brazilian moss flora: checklist, distribution and conservation. Nova Hedwigia 93(3-4): 277-334

CRUM, H. \& L. ANDERSON. 1981. Polytrichidae. In: Mosses of Eastern North America, Volume 2. Columbia University Press, New York.

DE LUNA, E., M. S. USSHER \& R. COBOS ACOSTA. 2002. Dos nuevos registros para la flora de musgos de Costa Rica: Steereobryon subulirostrum y Pogonatum pensilvanicum (Polytrichaceae). Acta Bot. Mex.60: 1-5.

DIXON, H. N. 1926. Studies in the bryology of New Zealand, with special reference to the herbarium of Robert Brown. Edited and published under the authority of the Board of Governors of the [New Zealand] Institute. No. 3: 234.
FRYE, T. C. 1948. Atrichum subulirostrum. Bryologist. 51(3): 186-188.

GOFFINET, B., W. R. BUCK, \& A. J. SHAW, 2009. Morphology, anatomy, and classification of the Bryophyta. In: Goffinet, B. \& A.J. Shaw, Bryophyte Biology. Cambridge University Press. p. 56-138.

GRADSTEIN, S. R., S. P. CHURCHILL \& N. SALAZAR-ALLEN. 2001. Guide to the Bryophytes to Tropical America. Mem. New York Bot. Gard. 86: 1-577.

GRIFFIN, III, D.. 1975. Additions to the Moss Flora of Venezuela. Bryologist (78) 2: 212-215

HAMPE, E. 1865. Prodromus Florae Novo-Granatensis. J. Triana et J.E. Planchon: Musci. Ann. Sci.Nat., Bot. V, Pp. 345-351

HARVARD UNIVERSITY, 2015, Harvard University Herbaria \& Libraries, Index of Botanical Specimens. Specimen: FH: 00213451 Lindig 2127, Colombia: consultado el 7 de junio de 2015. http://kiki. huh.harvard.edu/databases/specimen_search. php? mode $=$ details\&id $=25554$.

HERMANN, F. J. 1976. Recopilación de los musgos de Bolivia. Bryologist 79 (2): 125-171

HOOKER,W. J. 1847. Brief characters of some New Mosses, collected in New Granada by Mr. W. Purdie, indicated by W. Wilson. London J. Bot. 6. Pp. 289292

HYVÖNEN, J. 1989. A synopsis of genus Pogonatum (Polytrichaceae, Musci). Acta Bot. Fenn.138: 1-87.

HYVÖNEN, J. 2012. Australian Mosses Online. 48. Polytrichaceae. http://www.anbg.gov.au/abrs/ Mosses_online/Polytrichaceae.pdf

HYVÖNEN, J., T A. HEDDERSON, G L. SMITH MERRILL, J. G GIBBINGS \& S. KOSKINEN. 1998. On Phylogeny of the Polytrichales. Bryologist (101) 4: 489-504

HYVÖNEN, J., S. KOSKINEN, G. L. SMITH MERRILL, T. A. HEDDERSON \& S. STENROOS. 2004. Phylogeny of the Polytrichales (Bryophyta) based on simultaneous analysis of molecular and morphological data. Molec. Phylogen. Evol.31: 915-928

MATTERI, C. \& M. M. SCHIAVONE. 2002. Catálogo de los musgos (Bryophyta) de la Región Fueguina en Argentina y Chile. Revista Mus. Argent.Ci. Nat., N. S. 4(2): 111-138.

MENZEL, M. 1985. Die gattung Pogonatum P. Beauv. (Polytrichales, Musci) in Lateinamerika 1. Taxonomie und geographie von Pogonatum campylocarpum (C.Muell.) Mitt. und P. subflexuosum (Lor.) Broth. Lindbergia 11 (2/3): 134-140.

MENZEL, M. 1987. The genus Pogonatum P. Beauv. (Musci: Polytrichales) in Latin America 3.Taxonomy and geography of Pogonatum semipellucidum (Hampe) Mitt. Lindbergia 13: 75-78. 
MESSMER, L. \& T.C., FRYE. 1947. The Polytrichum juniperinum Group between South America and the United States. Bryologist 50 (3): 259-268

MITTEN, G. 1869. Musci Austro-Americani. J. Linn. Soc., Bot.12:604-622.

MORALES, T. \& M. GARCÍA. 2006. Catalogo anotado de las especies venezolanas de musgos (Bryophyta) pertenecientes al Herbario Nacional de Venezuela (VEN). Trop.Bryol. 28: 103-147 (134-135)

MULLEN, D. \& T.C. FRYE. 1947. Middle and South American Species of Oligotrichum. Bryologist 50 (1): $67-79$

NYHOLM, E. 1971. Studies in the genus Atrichum P. Beauv. Lindbergia 1: 1-33.

O'SHEA, B. 2010. Mosses of Venezuela. Arch. Bryol.75. Pp. 1-23

PERALTA, D. F. \& O. YANO. 2010. Taxonomic treatment of the Polytrichaceaea from Brazil. Bryologist 113 (3): 646-672

PURSELL, R. 1973. Un censo de los musgos de Venezuela. Bryologist (76) 4: 473-500 (496).

SASTRE DE JESÚS, I. \& W. R. BUCK. 1993. Annotated checklist of the mosses of Puerto Rico. Caribb. J. Sci. 29: 226-234

SCHIAVONE, M. M. 1978. Las Polytrichaceae del noroeste argentino. Lilloa 35(1): 31-65

SCHIAVONE, M. M. 1993. Bryophyta Musci: Polytrichinales. En Guarrera, S.S. I. Gamundi de Amos \& C. Matteri (Eds.) Flora Criptogámica de Tierra del Fuego. Consejo Nacional de Investigaciones Científicas y Técnicas de la República Argentina, Buenos Aires, 14 (12): 1-61.
SCHWÄGRICHEN, C. F. 1830. Species muscorum frondosorum. Pars I. En: Species Plantarum. Olim curante Carolo Ludwigio Willdenow. Tomus V. P.2. Sectio prima. Berolini Impresis G.C. Nauck. Pp. $1-21$

SMITH, G. L. 1971. A conspectus of the genera of Polytrichaceae. Mem.New York Bot. Gard. 21: 1-83.

SMITH, G. L. 1975. Neotropical Polytrichaceae I, II. Bryologist 78 (2): 201-204

SMITH, G. L. 1994. Polytrichidae. In: The Moss flora of México. Ed. A. Sharp, H. Crum \& P. Eckel. Part two. Mem. New York Bot. Gard. 69. The New York Botanical Garden.

STEERE, W. 1948. Contribution to the Bryogeography of Ecuador. I. A Review of the Species of Musci Previously Reported. Bryologist (51) 3: 65-167.

URIBE M. J. 2008. Monografía de Frullania subgénero Meteoriopsis (Frullaniaceae, Marchantiophyta). Caldasia 30(1): 49-94.

Recibido el 1 de marzo de 2017, aceptado el 8 de junio de 2017. 